\title{
"Die Ehre ist - die Ehre". Minna von Barnhelm aus der Perspektive des Moralisten La Rochefoucauld
}

\author{
Hansgerd Delbrück
}

Vor zehn Jahren hat Horst Steinmetz die Feststellung gemacht, daß Minna von Barnhelm eine erstaunlich "schwierige" Komödie sei, da sie trotz immer gleich hoher Wertschätzung die Interpreten zu immer neuen und dann doch wieder nur scheinbar endgültigen Deutungen provoziere. Zu den nicht endgültig, nicht eindeutig lösbaren Problemen, die als solche für ihn ein Charakteristikum dieses Lustspiels sind, rechnet er offenbar das Motiv der Ehre, zu dem er sich ausdrücklich jeder Deutung enthalten möchte. ${ }^{1}$ Wie zu erwarten, ist die Frage der Ehre dann doch von anderer Seite mehrfach wieder aufgegriffen worden, und auch in diesem Beitrag sei nun ein weiterer Erklärungsversuch unternommen. Er mag die Diskussion weiterführen, auch wenn er nicht beansprucht, das letzte Wort zu sprechen. Zumindest kann er zeigen, daß in einem bestimmten Bereich am Ende manches Schwierige so schwierig gar nicht ist. ${ }^{2}$

Von welchem Bereich ist die Rede? Da im Stück beide Hauptfiguren die Rolle des bzw. der Schwierigen zu spielen haben, sollte man sich die Aufklärung ihrer Schwierigkeiten von vornherein nicht so sehr von ihnen selbst erwarten, als vielmehr von einer kompetenteren, neutralen Instanz, nämlich vom Zuschauer selbst. Der aber kann seine Aufgabe nur dann erfüllen, wenn er dafür mit dem Werkzeug einer adäquaten Psychologie ausgerüstet ist. Die Psychologie des französischen Moralisten La Rochefoucauld, mit der das hier versucht werden soll, war bei Abfassung des Lustspiels schon fast neunzig Jahre alt. ${ }^{3}$ Sie konnte von Lessing - zumindest in ihren Grundzügen - wohl noch weitgehend als Bestandteil der von der Maximen-Literatur geprägten moralischen Bildung seiner Zeit vorausgesetzt werden. Doch gehörte es ja zu Lessings vornehmsten Stilprinzipien, es dem Leser wie dem Zuschauer so leicht wie möglich zu machen. Man mußte also damals keineswegs La Rochefoucauld gelesen haben, um Minna von Barnhelm zu verstehen, und man muß es auch heute nicht. Ein gutes Hilfsmittel aber bleiben La Rochefoucaulds Maximen gleichwohl - wie auch umgekehrt die Lektüre des Stücks dazu helfen kann, Lessings Deutung der Maximen zu verstehen.

Ich gehe mithin davon aus, daß La Rochefoucauld wirklich entscheidend zu Lessings neuer Lustspielpsychologie beigetragen hat. Einen direkten Nachweis dafür gibt es nicht: als gewiß kann man offenbar nur unterstellen, daß Lessing La Rochefoucauld 
gekannt hat und sich seiner herausragenden Stellung in der Maximen-Literatur bewu Bt war. ${ }^{4}$ Den indirekten Nachweis der unmittelbaren Bedeutung für das Stück liefert aber die in Minna von Barnhelm eigentlich ganz unübersehbare Psychologie La Rochefoucaulds, die freilich als solche wiederum nur durch die Stringenz der aus seinem Werk zur Interpretation herangezogenen Parallelen evident gemacht werden kann. Die Fülle der sich hier aufdrängenden Parallel-Zitate erhöht die Qualität des indirekten Beweises nicht nur an sich, sondern vor allem bei Berücksichtigung der Tatsache, daß alle Versuche einer Gegenprobe, nämlich andere französische Moralisten mit meist erheblich umfangreicherem Oeuvre zur Interpretation dieses Lustspiels heranzuziehen, zu keinerlei nennenswertem Resultat führen.

Dabei könnte es so scheinen, als hätte Lessing, wo er an anderer Stelle seines Werks La Rochefoucauld expressis verbis enwähnt, jeden Zusammenhang seines Lustspiels mit den Maximen des französischen Moralisten von vornherein ausgeschlossen. Die inkriminierende Aussage stammt jedoch nicht von Lessing, sondern von Chassiron. Sie findet sich in der von Lessing im Jahre 1754 in der Theatralischen Bibliothek herausgegebenen Übersetzung der Réflexions sur le Comique-larmoyant. Darin wandte sich Chassiron gegen die These, die "wesentliche Beschaffenheit" der Komödie bestehe in der "Schilderung so wohl der guten, als schlechten Eigenschaften" der Menschen, und der Einwand betraf die Definition der Komödie als dramatischer Gattung: "Die Menschen malen, und ihre Gemütsarten mit Genauigkeit ausdrücken, ist ein Zweck, den auch die la Rochefoucaults [sic!] und die la Bruyére [sic!] mit ihr gemein haben, die uns zwar Gemälde von Lastern und Tugenden überhaupt, niemals aber dramatische Gedichte haben liefern wollen. Die Schilderungen der guten und bösen Eigenschaften macht [sic!] also nicht an und für sich selbst das Wesen der Komödie aus; die Wahl und die Mischung der Farben, die Stellung und der Ausdruck der Personen, diese sind es, die ihr vornehmlich Namen, Form und Wesen erteilt haben." 5 Untersucht man dagegen Lessings eigene Lustspielpraxis in Minna von Barnhelm, so scheint er im Oeuvre La Rochefoucaulds keineswegs nur statische "Gemälde" von Tugenden und Lastern gesehen, vielmehr gerade umgekehrt in der dort vorgefundenen Psychologie Anregungen für die Dramaturgie seines Lustspiels gefunden zu haben.

Das Ziel der Untersuchung liegt aber natürlich nicht im Quellennachweis, sondern im besseren Verständnis des Stücks.

Der französische Moralist, illusionslos wie kaum ein anderer, hat seiner 
Maximen-Sammlung das Motto vorangestellt: "Unsere Tugenden sind meist nur verkappte Laster". Wie er sich und seinen Lesern mit scharfsichtiger Wahrheitsliebe die Augen über menschliche Verblendung zu öffnen sucht, das gibt seiner Sammlung im Vergleich zu den "Charakter"-Beschreibungen von Theophrast bis La Bruyère den unverkennbar eigenen, aristokratisch-überlegenen Ton. Theophrast wie La Bruyère schildern immer wieder die alltäglichen Verfehlungen im Bereich des allzu Menschlichen; der Tenor ist dabei, daß man anständigerweise gegen seine Fehler angehen sollte, ohne aber widrigenfalls einen anderen Tadel als das Lächeln eines zuletzt doch nachsichtigen Einverständnisses gewärtigen zu müssen: so sind die Menschen, und sie werden sich nicht ändern. Diese Nachsicht gegenüber der Unvermeidlichkeit menschlicher Schwächen fehlt bei La Rochefoucauld. Wo bei Theophrast oder La Bruyère das Laster auf einem Mangel an moralischem Einsatz beruht, setzt er die bewußte, positive moralische Anstrengung voraus, um gerade in ihr das gleichwohl zugrunde liegende Laster zu entlarven. Sein Verständnis menschlicher Schwäche (faiblesse) zielt also nicht etwa nur auf eine Schwäche des Willens. Aber auch nicht nur - wie von der fortschrittsgläubigen Aufklärung gern unterstellt - auf Erkenntnisschwäche, der durch Belehrung und Erziehung schließlich beizukommen wäre. Verblendung sieht er statt als Ursache eher als Folge und Ausdruck von Lastern: "Die Verblendung des Menschen ist die gefährlichste Wirkung ihres Dünkels [orgueil]; sie dient dazu, ihn zu nähren und zu steigern, und nimmt uns die Kenntnis der Mittel, die unser Elend lindern und uns heilen könnten von unsern Fehlern." (Nr. 585; Sch., S. 99) ${ }^{6}$ Letzte Ursache der Verfehlung bleibt der Dünkel, der falsche Stolz. Gegen ihn hilft nur das Bewußtsein der Schwäche, die "Demut" (humilité): "Demut ist das wahre Kennzeichen christlicher Tugenden. Ohne sie bleiben uns alle unsere Fehler, und sie werden nur vom Stolz bedeckt, der sie andern und auch uns selbst verbirgt." (Nr. 358; Sch., S. 77)

Der Stolz als Kardinalsünde des Menschen - daran scheint an sich noch nichts sonderlich bemerkenswert. Hybris bzw. Superbia sind seit eh und je Grundbegriffe der christlichen Tugendlehre ebenso wie der sich auf antike Tradition berufenden Dramaturgie. Doch nach La Rochefoucauld liegt unserem (falschen) Stolz zuletzt Eigenliebe (amour-propre) zugrunde. Auch dieser Begriff hat zwar eine lange, in die Antike zurückreichende Tradition, ist aber bei La Rochefoucauld auf eine sehr spezifische Weise zum Zèntralbegriff seiner Psychologie wie seiner Kritik der Moral ausgebildet. Schon die erste Maxime der ersten Ausgabe von 1655 begann folgendermaßen: "Eigenliebe ist Liebe [des Menschen] zu sich selbst und zu allen 
Dingen um seinetwillen; sie macht die Menschen zu Selbstanbetern und würde sie zu Tyrannen über andere machen, wenn das Schicksal ihnen die Mittel dazu gäbe. Sie verweilt niemals außer sich und streift fremde Gegenstände nur [...], um das ihr Eigene zu gewinnen. Nichts ist so stürmisch wie ihre Wünsche, nichts so verborgen wie ihre Absichten, und nichts so verschlagen wie ihre Handlungsweise. [...] Man kann weder die Tiefen ihrer Abgründe ermessen noch die Finsternisse durchdringen. Dort unten lebt sie, den schärfsten Augen verborgen [...] Dort ist sie oft unsichtbar sich selber, dort empfängt, nährt und bildet sie, ohne es zu wissen, unzählige Regungen von Liebe und $\mathrm{HaB}$, und so ungeheuerliche, daß sie sie nicht erkennt, oder sich nicht entschließen kann, sie einzugestehen, wenn sie sie ans Tageslicht heraufgelassen hat [...]". (Nr. 563; Sch., S. 95)

Von besonderem Gewicht ist in diesem Zitat die Behauptung, daß der amour-propre mit Vorliebe unbewußt ("oft unsichtbar sich selber") unter der Maske der Tugend "verborgen" lebt. Es ist gerade diese Optik, unter der sich im folgenden die Entlarvung der falschen Tugenden nicht nur Tellheims, sondern auch Minnas als das entscheidende dramaturgische Prinzip des Lustspiels erweisen wird. Diese Entlarvung, durch die den Protagonisten ebenso wie den Zuschauern die Augen geöffnet werden sollen, erscheint zugleich als therapeutischer Prozeß, der die Verwandlung der falschen Tugenden ("Leidenschaften") in "tugendhafte Fertigkeiten" ermöglicht. Wenn Lessing dieses zuletzt genannte Ziel im 78. Stück der Hamburgischen Dramaturgie bei seiner Deutung des Aristotelischen Tragödiensatzes als das Ziel der Tragödie angibt, so spricht das nicht gegen eine parallele Zielsetzung seines Lustspiels. Im 77. Stück steht ja auch der andere Satz: "Bessern sollen uns alle Gattungen der Poesie: es ist kläglich, wenn man dieses erst beweisen muß; noch kläglicher ist es, wenn es Dichter gibt, die selbst daran zweifeln." Die daran anschließende Differenzierung wirkt künstlich, und wie der mit "wenigstens" eingeleitete Nachsatz zeigt, hatte Lessing seine eigenen Schwierigkeiten damit: "Aber alle Gattungen können nicht alles bessern; jedenfalls nicht jedes so volkommen wie das andere [...]" Man muß da ohne Zweifel Steinmetz recht geben, der feststellt, daß Lessings Theorie hinter seiner Praxis zurückblieb. ${ }^{7}$

Es ist aber im folgenden nur Lessings schriftlich fixierte Theorie, die aus der Untersuchung weitgehend ausgeklammert werden soll, und zwar zugunsten der aus dem Stück selbst abgeleiteten Lustspielpsychologie. Nicht diese selbst fand Lessing bei dem Moralisten vor, wohl aber eine Psychologie, die er in seinem Lustspiel anwenden und dadurch in Lustspielpsychologie verwandeln konnte. So bleiben mithin für Minna von Barnhelm lustspieldramaturgische Erkenntnisse Lessings vorausgesetzt, für die es bei 
La Rochefoucauld keine Analogien gibt. Und doch spricht vieles dafür, daß die Maximen, mit ihrer Betonung der unter den Tugenden verborgenen Laster, dem Dichter auf seinem Weg zur Erkenntnis der Komödie als einer umgedrehten (nämlich nur gespielten und vorgetäuschten) Tragödie ${ }^{8}$ zumindest entgegenkamen. Tellheim schildert sich selbst in der Szene II,9 als den vom Schicksal Geschlagenen in einer Weise, daß Minna ironisch erklärt: "Das klingt sehr tragisch!", und Minna selbst wählt in der Szene IV, 6 einen "wahrhaft tragischen Abgang", ${ }^{9}$ als sie behauptet, ihn nicht heiraten zu können und zu dürfen. Natürlich heißt "tragisch" hier in erster Linie Furcht erregend. Dabei ist es jedoch vor allem dasMitleid, (jene zweite zentrale Kategorie der Aristotelischen Tragödiendefinition), das den beiden ${ }^{10}$ Protagonisten zwar nach außen hin zum Tugendprinzip dient, von der Lustspiel-Handlung aber als Pseudotugend entlarvt wird. Diese Pseudotugend ist es, die ihre Liebe zuletzt doch am meisten behindert und von der sie kuriert werden müssen, sollen sie - über ein "gereinigtes" Mitleid - wieder zueinander finden.

III

La Rochefoucauld sieht eine besonders innige Verbindung der Eigenliebe mit der "Leidenschaft" der Liebe. Von leidenschaftlicher Liebe wird man zu Beginn des Stücks bei Tellheim natürlich nicht sprechen wollen, aber gerade für solche spezifisch Teltheimsche Verkümmerung der Liebe hat La Rochefoucauld die Eigenliebe als Erklärung parat. "In keiner Leidenschaft", stellt er fest, "herrscht die Eigenliebe mächtiger als in der Liebe, und stets ist man eher geneigt, die Ruhe derer, die man liebt, zu opfern, als die seine zu verlieren." (Nr. 262; Sch., S. 70) Der zentrale Begriff dieses Satzes, Ruhe (bzw. repos) ist dabei verstanden als eine Haltung, die durchaus sehr aktiv auf den eigenen Vorteil bedacht sein kann, wo sie nach außen hin darüber erhaben scheint. In den Worten von La Rochefoucauld: "Unter allen Leidenschaften kennen wir die Lässigkeit [paresse] am schlechtesten. Sie ist die glühendste und bösartigste von allen, obwohl ihr Einfluß unmerklich und der Schaden, den sie stiftet, sehr verborgen ist. Wenn wir aufmerksam ihre Macht untersuchen, so werden wir erkennen, daß sie sich bei jeder Gelegenheit zum Herrn über unsere Gefühle, unsern Vorteil und unsere Freuden zu machen versteht. [...] Die Ruhe der Trägheit [le repos de la paresse] ist eine heimliche Verzauberung unserer Seele, die auf einmal die glühendsten Vorsätze und festesten Entschlüsse preisgibt." (Nr. 630; Sch., S. 103)

Nach Tellheims eigener Erklärung gegenüber Minna und gegenüber sich selbst ist es 
die "Ehre", um deretwillen er seine Veriobung - bei jedem ernsthaften Bräutigam ein Musterbeispiei der "glühendsten Vorsätze und festesten Entschlüsse" - mit Minna lösen will. Was er aber unter "Ehre" versteht, kann er dabei so wenig einleuchtend definieren, daß Minna es auch nicht für einen Moment ernstnehmen möchte. Verächtlich weist sie seine Begründungs- und Erklärungsversuche als inhaltslose Tautologie zurück: "Nein, nein, ich weiß wohl.- Die Ehre ist - die Ehre."11 Setzt man jedoch für das Wort "Ehre" jene von La Rochefoucauld angesprochene Verzauberung der Seele ein, die aus dem amour-propre folgt, dann können wir, Schritt für Schritt, genau benennen, wofür Tellheim die Worte fehlen und wofür Minna mit ihrem ungeduldigen "Die Ehre ist - die Ehre" so wenig Verständnis aufbringt.

Denn worin genau besteht seine Verzauberung? Das Ziel der Zufriedenheit mit sich selbst, in dessen Dienst er seine Leidenschaft für Minna so schnell vergaß, hat von ihm verlangt, stattdessen einer anderen Leidenschaft zu frönen: Anerkennung und Gerechtigkeit bei seinem König zu finden. Zumal in diesem Zusammenhang spricht er von Ehre: "Sie haben mich nicht ausreden lassen. - Ich wollte sagen: wenn man mir das Meinige so schimpflich vorenthält, wenn meiner Ehre nicht die vollkommenste Genugtuung geschieht; so kann ich, mein Fräulein, der Ihrige nicht sein. ${ }^{12}$ Bei La Rochefoucauld heißt es: "Nichts schmeichelt mehr unserm Stolz als das Vertrauen der Großen, weil wir es für eine Wirkung unseres Verdienstes halten [...]" (Nr. 239; Sch., S. 68)

Offenbar ist es im Fall der Doppel-Beziehung Tellheims zu Minna und dem preußischen König ${ }^{13}$ zu einem Konflikt gekommen, wobei es sich um so etwas wie konkurrierende Liebe handelt, auch wenn diese Liebe ganz unterschiedlicher Natur ist. In solchem Konfliktsfall wird, nach La Rochefoucauld, die Eigenliebe gerade die Liebe dessen vorziehen, der seine Liebe verweigert: "In der Liebe kaum zu lieben, ist ein sicheres Mittel, geliebt zu werden." (Nr. 636; Sch., S. 104) Von dieser Maxime aus ist Tellheims Entscheidung für den preußischen König - und das heißt für den Kampf um dessen Liebe (oder prosaischer: Gunst bzw. "Vertrauen") - ebenso leicht psychologisch zu begründen wie die leichtfertige Aufkündigung der Verlobung mit Minna.

Genauso ist diese Maxime dann der Hintergedanke, aus dem heraus Minna handelt, als sie vorgibt, daß nun auch sie Tellheim aufgeben müsse. Wenn sie dabei als die von ihrem Onkel angeblich Enterbte zugleich an sein Mitleid appelliert, dann eben damit auch an seine Eigenliebe: "Die Großherzigkeit wird schon durch ihren Namen erklärt, dennoch könnte man sagen, sie sei Scharfsinn des Stolzes und das edelste Mittel, 
bewundert zu werden." (Nr. 285; Sch., S. 72) Noch lapidarer erklärt La Rochefoucauld: "Die Tugenden verlieren sich im Eigennutz, wie die Ströme sich im Meer verlieren." (Nr. 171; Sch., S. 61) Und: "Tugend ginge nicht so weit, wenn Eitelkeit ihr nicht Gesellschaft leistete" (Nr. 200; Sch., S. 63), oder schließlich: "Was man Freigebigkeit nennt, ist fast immer eine Eitelkeit, die das Geben lieber hat als die Gaben." (Nr. 263; Sch., S. 70) ${ }^{14}$ Ich kann mir hier ersparen, alle die Beispiele für Tellheims einseitige Vorliebe für das Geben und seine Gleichgültigkeit gegenüber den von ihm verteilten Gaben aufzuführen. Stattdessen komme ich gleich zu dem Umstand, daß er dann um Minnas willen sofort und wie erwartet auf seine ihm doch so wichtigen finanziellen Forderungen an den preußischen Staat verzichten kann. Es sind immerhin Forderungen, durch deren Nichterfüllung er so empfindlich in seiner Ehre gekränkt wurde, daß er ihretwegen Minna die Verlobung aufkündigte. Wenn er nun so plötzlich auf diese ihm zustehenden Außenstände verzichtet, dann dürfen wir nach La Rochefoucauld von vornherein sicher sein, daß sein Verlust in jedem Falle durch etwas anderes wettgemacht ist: "Immer hält sich der Stolz schadlos und verliert nichts, selbst wenn er auf Eitelkeit verzichtet." (Nr. 33; Sch., S. 50) Da Minna hier seines Beistands zu bedürfen scheint - so wie das Mitleid zuvor von ihm forderte, daß er sie um ihretwillen verlie $B$-, kann es ihm nun nur umso lieber sein, wenn er, um zu ihr zurückkehren zu können, auf seine Forderungen an den preußischen König verzichten muß. Ist es doch überall und immer wieder sein uneigennütziges Mitleid, das er unter Beweis zu stellen versucht, seit ihm in seinem Ehrenhandel mit dem preußischen Staar der Vorschuß an die Sächsischen Stände als Mitleid aus Eigennutz ausgelegt worden war.

Daß der Stolz als das verborgene Motiv von Tellheims Ehrbegriff zu werten ist, weiß auch Minna, und sie betont es ausdrücklich und wiederholt, auch ohne dabei sein Verhältnis zum preußischen König im Sinn zu haben: "Bloß ein wenig zu viel Stolz, Franziska, scheint mir in seiner Aufführung zu sein. Denn auch seiner Geliebten sein Glück nicht wollen zu danken haben, ist Stolz, unverzeihlicher Stolz." 15 Dieser Stolz aber ist aus der Sicht von La Rochefoucauld zuletzt auf Eitelkeit und Eigenliebe zurückzuführen. Und da es dabei um gekränkten Stolz geht, gilt dasselbe für seine Leiden. Sie sind Ausdruck des letztlich unbegründeten Selbstmitleids: "Was für Gründe wir auch unsern Leiden unterschieben - stets sind es Eigennutz und Eitelkeit [l'interêt et la vanité], die sie hervorbringen." (Nr. 332; Sch., S. 66) Tellheim, der von seinem Unglück weniger geschlagen ist, als daß er es zu gebrauchen und womöglich zu genießen scheint, und der an ihm festhält auch noch zu einer Zeit, als es längst 
widerlegt ist, tut all dies zur Bestätigung seines Selbstwertgefühls: "Wer Verdienste [du mérite] zu haben glaubt, macht sich eine Ehre [honneur] aus seinem Unglück [d'être malheureux], um anderen und sich selbst einzureden, daß er des Ringens mit dem Schicksal wert sei." (Nr. 50; Sch., S. 51) Das Selbstwertgefühl aber ist getroffen, wo wir mit einer eigenen Unvollkommenheit fertig werden müssen, und dabei zeigt sich, warum letztlich unsere Ehre, auf die sich unser Stolz beruft, nicht objektiv von äußeren Kriterien, sondern von unserem Selbstwertgefühl definiert ist: "Die Natur, die die Organe unseres Körpers zu unserm Glück so weise eingerichtet hat, hat uns auch den Stolz mitgegeben, um uns das schmerzliche Bewußtsein unserer-Unvollkommenheit [imperfections] zu ersparen." (Nr. 36; Sch., S. 50)

So gilt auch: "Wir versuchen, uns eine Ehre aus den Fehlern zu machen, die wir nicht ablegen wollen." (Nr. 442; Sch., S. 83) Das funktioniert dann allerdings meist auf indirektem Wege, denn: "Sich selbst zu betrügen, ohne es zu merken, ist so leicht, als es schwer ist, andere zu betrügen, ohne daß sie es merken." (Nr. 115; Sch., S. 56) So kommt es zu Selbstbetrug und zur Schönfärbung unserer Fehler gegenüber anderen: "Der Hang, von uns selbst zu sprechen und unsere Fehler nur in dem Licht zu zeigen, in dem wir sie sehen lassen wollen, macht einen großen Teil unserer Offenherzigkeit aus." (Nr. 383; Sch., S. 79) Wir sprechen deshalb zuweilen sogar gern von unseren Fehlern, aber: "Wir suchen eine Ehre in Fehlern, die unsern wirklichen entgegengesetzt sind [...]" (Nr. 424; Sch., S. 82)

La Rochefoucauld spricht in diesem Zusammenhang mehrfach von Rollenspiel: "Der Eigennutz", heißt es da etwa, "spricht alle Sprachen und spielt alle Rollen, selbst die des Uneigennützigen." (Nr. 39; Sch., S. 50) Allgemein gilt: "Man nimmt in jedem Stande eine Miene und Haltung ein, um zu scheinen, wofür man gehalten sein will, so daß man sagen kann, die Welt bestehe aus lauter Masken." (Nr. 256; Sch., S. 69) Insbesondere aber trifft dieses Merkmal auf den Stolz zu: "Demut ist oft nur eine erheuchelte Unterwerfung, um sich andere zu unterwerfen. Ein Kunstgriff des Stolzes, der sich erniedrigt, um sich zu erheben; und mag er sich auf tausend Arten verkleiden, niemals ist er besser verkappt und fähiger zu täuschen, als wenn er sich unter der Maske der Demut zeigt." (Nr. 254; Sch., S. 69) So spricht Tellheim - im Sinne dessen, der sich selbst herabsetzt, verkleinert - "demütig" von seinen Fehlern und "Gebrechen" und zielt dabei nach außen auf seine finanzielle Notlage und seine körperlichen Gebrechen. Daß er in Wahrheit trotz allem wesentlich ein "Verschwender" ist, hat Minna richtig erkannt - ein Verschwender nicht nur im Umgang mit Geld, sondern - und eben darüber hat Minna sich letztlich zu beklagen - mit 
ideellen Werten bis hin zur Liebe seiner Verlobten. Da natürlich keineswegs böse Absicht dahintersteht, ${ }^{16}$ handelt es sich dabei eher um so etwas wie ein seelisches Gebrechen, das er mit der Betonung des körperlichen nicht nur vor Minna, sondern auch vor sich selbst zu verbergen sucht.

\section{IV}

Welche Gebrechen der Zuschauer hier, mit La Rochefoucauld, für die schwereren halten soll, ist klar: die seelischen. Denn die zugehörige Maxime heißt: "Wir gestehen kleine Fehler nur ein, um glauben zu machen, wir hätten keine großen." (Nr. 327; Sch., S. 75) "Die Gesundheit der Seele" ist nach La Rochefoucauld "nicht verbürgter als die des Körpers. Scheint sie auch fern von allen Leidenschaften, so ist man nicht weniger in Gefahr, von ihnen fortgerissen als krank zu werden, wenn man gesund ist." (Nr. 188; Sch., S. 62) Oder: "Gebrechen der Seele sind wie Wunden des Körpers; so sorgfältig man sie auch heilen möchte, Narben bleiben immer, und jeden Augenblick sind sie in Gefahr, wieder aufzubrechen." (Nr. 194; Sch., S. 63) Die Folge der Enttäuschung, von Preußen verraten und "ins Elend" gestoßen zu sein, war ein seelisches, nicht das körperliche Gebrechen. ${ }^{17}$ So ist es auch das seelische Gebrechen, um dessentwillen Tellheim, nach dem 'Liebes-Entzug' des Königs, sein Verhältnis zum König über das zu Minna stellt und um seine Gunst so heftig buhlt, wie er die Liebe Minnas bedenkenlos verletzt: "Die Schmerzen der Schande und Eifersucht sind so heftig, weil die Eitelkeit nicht helfen kann, sie zu ertragen." (Nr. 446; Sch., S. 83) Der falsche Stolz ist letztlich verletzte Eitelkeit.

Doch welche Möglichkeiten der Heilung finden sich für seelische Gebrechen dieser Art in den Maximen des Moralisten? La Rochefoucauld scheint skeptisch, ja entschieden pessimistisch: "Schwachheit ist der einzige Fehler, den man nicht verbessern kann." (Nr. 130; Sch., S. 58) Gerade für Tellheims Verrat an Minna, Folge und Ausdruck seines seelischen Gebrechens, gilt ja der Satz: "Man begeht Verrat öfter aus Schwäche als aus einem vorsätzlichen Plan zu verraten." (Nr. 120; Sch., S. 57) Doch wird dieser Pessimismus in einem anderen Satz eingeschränkt: "Wenn wir unsern Leidenschaften widerstehen" - und die Möglichkeit ist damit immerhin angesprochen -, "danken wir es mehr ihrer Schwäche als unserer Stärke." (Nr. 122; Sch., S. 57) Und in wieder einer anderen Maxime findet sich die positive Möglichkeit eines Auswegs sogar im Indikativ des Hauptsatzes: "So schändlich wir uns auch betragen haben - fast immer steht es in unserer Macht, unsern guten Ruf wiederherzustellen." (Nr. 412; Sch., S. 81) 
Nicht nur das Programm der Entlarvung, sondern auch das der Heilung ist also aus den Maximen abzulesen. Was aber heißt, die Heilung steht in unserer Macht? Wie steht es mit Schicksal und Zufall? La Rochefoucaulds Urteile sind da keineswegs eindeutig; sicher ist ihm nur, daß es tatsächlich einen Zusammenhang zwischen all diesen Größen gibt. Was ist überhaupt jemals unsere eigene Leistung? "Obwohl die Menschen sich auf ihre großen Taten etwas zugute tun, sind diese doch meist nicht Resultat eines großen Vorsatzes, sondern des Zufalls." (Nr. 57; Sch., S. 52) Eine ähnliche Maxime lautet: "Man müßte bürgen können für sein Schicksal, um zu verantworten, was man tun wird." (Nr. 574; Sch., S. 98) Und: "Welch große Vorzüge auch die Natur gewähren mag, nicht sie allein, sondern sie und das Schicksal machen erst den Helden." (Nr. 53; Sch., S. 51) Hinzu aber kommt: "Glück und Unglück der Menschen hängen nicht weniger von ihrer Laune ab als von ihrem Schicksal" (Nr.; 61 Sch., S. 52), so daß beide unheilvoll zusammenwirken: "Zufall und Laune regieren die Welt." (Nr. 435; Sch., S. 83) Aber wieder relativiert La Rochefoucauld: "Die Launen unseres Gemüts sind noch seltsamer als die des Schicksals." (Nr. 45; Sch., S. 50) Das bedeutet nicht etwa nur eine Steigerung der Ausweglosigkeit und Determiniertheit des Menschen. Vielmehr gilt umgekehrt: "Kein Zufall ist so unglücklich, als daß kluge Leute nicht Vorteil daraus zögen, und keiner so glücklich, als daß unüberlegte ihn nicht zu ihrem Nachteil wenden könnten." (Nr. 59; Sch., S. 52) Entsprechend sollte auch das Schicksal nicht zu einer gänzlich unberechenbaren, ungerechten Größe dämonisiert werden. Denn zwar ist richtig: "Niemals erscheint das Schicksal so blind, als wenn es einem nicht wohlwill." (Nr. 391; Sch., S. 79) Doch ist das offenbar eine Frage der Optik, die über die wahre Folgerichtigkeit oder Blindheit des Schicksals keine korrekte Auskuntt geben kann.

Für La Rochefoucauld jedoch gibt es Schicksal eindeutig nicht nur als "fortune", sondern auch als "destinée": "Ungewißheit und Wechsel in der Welt mögen noch so groß erscheinen, trotzdem bemerkt man so etwas wie eine geheime Verkettung und eine von der Vorsehung bestimmte Gesetzmäßigkeit, die bewirkt, däß alles in seiner Reihe geht und der Bahn des Schicksals [le cours de sa destinée] folgt." (Nr. 613; Sch., S. 101) Der Offizier La Rochefoucauld wähit für seine Erklärung der übergeordneten Bahn des Schicksals ein Beispiel aus seinem eigenen Metier: "Wer den Sieg nur durch seine Entstehung erklären will, wäre wie der Dichter versucht, ihn einen Sohn des Himmels zu nennen, denn auf Erden entdeckt man seinen Ursprung nicht. Er wird in der Tat durch zahllose Handlungen herbeigeführt, die nicht auf ihn selbst, sondern auf das Sonderinteresse derer abzielen, die diese Handlungen begehen. Denn alle, aus denen 
eine Armee zusammengesetzt ist, denken an ihren eigenen Ruhm und an ihre Beförderung und fördern dabei doch ein so großes und so allgemeines Gut." (Nr.615; Sch., S.101-102)

Entscheidend scheint da, daß trotz der Schwäche des einzelnen sein Schicksal durch das Zusammenspiel des Ganzen sich positiv wenden kann. Und da "kluge Leute" aus der gegebenen Lage immer ihren Vorteil ziehen können, liegen genau hier die Möglichkeiten wie die Grenzen tätigen Mitleids. "Alle unsere Eigenschaften [qualités]", sagt La Rochefoucauld, "sind ungewiß und zweifelhaft, im Guten wie im Bösen, und fast alle sind das Spiel der Gelegenheit [à la merci des occasions]" (Nr. 470; Sch., S. 85) Wenn also das "Schicksal [fortune] unsere Tugenden und Laster erscheinen [läßt] wie das Licht die Gegenstände" (Nr. 380; Sch., S. 79), dann gibt es offenbar die Möglichkeit für die Mitmenschen, Schicksal zu spielen und "Gelegenheiten" zu schaffen, in denen und durch die sich Tugenden und Laster nicht nur zeigen, sondern überhaupt erst ins Gewisse und Unzweifelhafte entwickeln können. Tellheim, der sich über seine eigenen Motive und Ziele betrügt und damit in ein falsches, gewiß nicht gewolltes Geleise geraten ist, muß und kann mithin über seine besseren Ziele und Möglichkeiten aufgeklärt werden, wenn auch nicht so sehr durch sich selbst, als eben durch seine Partnerin. Das folgt aus der unterschiedlichen Fähigkeit der Menschen, sich selbst und andere zu beurteilen - noch einmal ist die Maxime Nr. 115 zu zitieren: "Sich selbst zu betrügen, ohne es zu merken, ist so leicht, als es schwer ist, andere zu betrügen, ohne daß sie es merken." Es geht um Aufdeckung von Verborgenem, zugleich aber um die Anwendung von List oder doch mindestens das Beschreiten indirekter Wege, denn: "Was uns gewöhnlich hindert, unsere Freunde auf den Grund unseres Herzens blicken zu lassen, ist nicht so sehr Mißtrauen gegen sie als gegen uns." (Nr. 315; Sch., S.74)

Was wir freilich unseren Mitmenschen und was diese wiederum uns voraushaben, das ist nur der sichere Blick für das Betrugsverfahren und Selbstbetrugsverfahren als solches - ob letztlich Tugend oder Laster zugrundeliegt oder sich durchsetzten wird, bleibt offen und bemißt sich ganz danach, ob beim anderen soviel Tugend vorhanden ist, daß die geschaffene "Gelegenheit" sie ans Licht fördern kann.

Die Tugend Tellheims, um die es Minna hier zu tun sein muß, ist - bei allen Vorbehalten gegenüber diesem großen Wort - seine Liebe zu ihr, nicht seine weiterhin nur verbal behauptete, sondern die wahre, mit der er sich zuletzt wirklich für die Verlobte entscheidet. Als ihre Intrige zum Schluß Erfolg hat, nachdem sie zuvor fast zu scheitern drohte, erklärt sie: "Nein, ich kann es nicht bereuen, mir den Anblick lhres ganzen Herzens verschafft zu haben: - Ah, was sind Sie für ein Mann!"18 Entsprechend 
heißt es bei La Rochefoucauld: "Gibt es eine reine Liebe, in die sich gar keine andern Leidenschaften einmengen, so hält sie sich, uns selber unbekannt, im innersten Herzen verborgen." (Nr. 69; Sch., S. 53) Es ist jedoch die Frage, ob das, was Minna bei Tellheim zu ihrer Freude 'sehen' dart, als er sich trotz des scheinbaren Beweises ihrer Untreue für sie entscheidet, wirklich aus der Optik von La Rochefoucauld mit dem Namen der Liebe richtig belegt ist. Es spricht im Gegenteil vieles dafür, daß Tellheim schon mit seiner Entscheidung für seinen Kampf mit Preußen und gegen die Verlobung, nach den Denkkategorien La Rochefoucaulds wie Lessings, zunächst gegen die Gebote nicht so sehr der Liebe, als vielmehr der Freundschaft versto Ben hat. Für die Liebe nämlich gilt: "Da es einem niemals freisteht, zu lieben oder aufzuhören zu lieben, kann weder der Liebhaber sich mit Recht über die Unbeständigkeit [l'inconstance] seiner Geliebten beklagen noch sie sich über die Flatterhaftigkeit des Liebhabers." (Nr. 577; Sch., S. 98) Anders dagegen steht es mit der Freundschaft, und La Rochefoucauld wertet sie offenbar keineswegs geringer als die Liebe, eher höher: "So selten die wahre Liebe ist - wahre Freundschaft ist noch seltener." (Nr. 473; Sch., S. 85) Auch für die Freundschaft gilt, fast analog, was La Rochefoucauld über den Ort der "reinen Liebe" im "innersten Herzen" gesagt hatte. Eine entsprechende Maxime lautet: "Wir sind so veränderlich in unsern Freundschaften, weil es schwer ist, die Eigenschaften der" Seele, und leicht, die des Verstandes kennenzulernen." (Sch., S. 53)

Dabei hat es mit der Freundschaft formal eine ganz einfache Bewandtnis: " Was die Menschen Freundschaft genannt haben, ist nur eine Zweckgemeinschaft zur gegenseitigen Interessenschonung und zum Austausch guter Dienste; es ist ein Geschäft, von dem der Eigennutz sich immer irgendeinen Gewinn verspricht." (Nr. 83; Sch., S. 54) Indessen hat hier der Eigennutz offenbar bisweilen Schwierigkeiten mit sich selbst, denn "Eigenliebe vergrößert oder verkleinert uns die guten Eigenschaften unserer Freunde, je nach unserer Zufriedenheit mit ihnen, und wir beurteilen ihre Verdienste nach ihrem Benehmen gegen uns." (Nr. 88; Sch., S. 54) Die Verzerrung der subjektiven Perspektive ist dabei im Extremfall von der Leistung des Gegenübers ganz unabhängig, der Verurteilte allein das Opfer des Urteilenden und dieser das Opfer seiner selbst: "Man ist untröstlich, von seinen Feinden betrogen und von seinen Freunden verraten zu werden, aber oft sehr befriedigt, beides durch sich selber $z u$ sein." (Nr. 114; Sch., S. 56) Der Eigennutz als Modus der Freundschaft, von dem die Maxime Nr. 83 spricht, muß deshalb - und hier liegt jedenfalls die eigentliche Tugend und moralische Leistung der Freundschaft - gleichsam ein Eigennutz höherer Ordnung sein. Es muß uns nämlich gelingen, die Freunde über uns selbst zu stellen: "Wir lieben 
alles nur im Hinblick auf uns, auf unsern Geschmack, und wir folgen unserm Vergnügen, wenn wir unsere Freunde uns selber vorziehen, und doch kann nur durch dieses Vorziehen Freundschaft wahr und vollkommen werden." (Nr. 81; Sch., S. 54)

So handelt es sich also in der Ökonomie der Freundschaft um die Notwendigkeit gleichsam einer grundsätzlichen Vorgabe an den Freund. Sie ist als echte Freigebigkeit dem Neid entgegengesetzt: "Wahre Freundschaft verdrängt den Neid." (Nr. 376; Sch., S. 78) Sie hat nichts mit der falschen Freigebigkeit gemein, über die oben schon das Wort La Rochefoucaulds zitiert wurde, sie sei "fast immer eine Eitelkeit, die das Geben lieber hat als die Gaben." (Nr. 263; Sch., S. 70)

Das Pendant zum Neid in der Freundschaft ist indessen in der Liebe die Eifersucht, und von der Liebe muß hier nun doch wieder die Rede sein, sofern sie nämlich versuchen kann, sich die Gesetze der Freundschaft zunutze zu machen. "In der Eifersucht liegt mehr Eigenliebe als Liebe" (Nr. 324; Sch., S. 75), deshalb ist "eine Art von Liebe" zu fordern, "deren Übermaß keine Eifersucht aufkommen läßt." (Nr. 336; Sch., S. 75) Es klingt fast wie ein Rechenexempel: "Untreue müßte die Liebe auslöschen, und daher sollte man nie eifersüchtig sein, wenn man Grund dazu hat. [sic!]" (Nr. 359; Sch., S. 77) Wenn denn also Minna, wie Generationen von Interpreten aufgefallen ist, so viel klüger wirkt als Tellheim, dann liegt es offenbar daran, daß sie sich im Unterschied zu ihrem Verlobten in ihrem Verständnis der Liebe eher auf der Höhe von La Rochefoucaulds Einsichten zu bewegen scheint. Sie vermeidet bewuBt alle Fehler der Eifersucht, für die sie doch jeden Grund hätte und die sich Tellheim (gegenüber dem 'ungetreven' preußischen König) so starrsinnig auch noch als sein Verdienst anrechnet. Sie scheint zu wissen, daß seine Eifersucht nicht nur Ausdruck seiner Eigenliebe ist, sondern daß er an dieser Eifersucht leidet: "Eifersucht ist das größte aller Leiden [...]" (Nr. 503; Sch., S. 88) Die Fortsetzung der Maxime La Rochefoucaulds lautet: "[...] und erregt dennoch bei den Personen, die es verursachen, das geringste Mitleid." Minna kann Mitleid mit Tellheim empfinden, weil es eben nicht sie, sondern der preußische König ist, der Tellheims Ejfersucht ausgelöst hat. Und wenn sie tätiges Mitleid üben kann, um ihn von seinem Leiden zu befreien, dann bestätigt sie damit La Rochefoucaulds Maxime: "Es ist weit leichter, für andere als für sich weise zu sein." (Nr. 132; Sch., S. 58) Sie scheint zu wissen, was ihm fehlt und was wir bereits oben zu Beginn zitierten: "Die Verblendung der Menschen ist die gefährlichste Wirkung ihres Dünkels; sie dient dazu, ihn zu nähren und zu steigern, und nimmt uns die Kenntnis der Mittel, die unser Elend lindern und uns heilen könnten von unsern Fehlern." (Nr. 585; Sch., S. 99) Da sie nicht verblendet ist wie Teliheim, 
der nichts weiß von seinem "Dünkel" - was läge näher, als in der von ihr geplanten "Lektion"19 die Mittel nicht der Liebe, sondern der Freundschaft für inn einzusetzen? "Auf der höchsten Stufe der Freundschaft", schreibt La Rochefoucauld, "offenbaren wir dem Freunde nicht unsere Fehler, sondern die seinen." (Nr. 410; Sch., S. 81)

\section{$\mathrm{V}$}

So einfach aber verhält es sich mit Minnas Charakter dann doch wieder nicht: ihre Selbstsicherheit (nach Goethe: Überlegenheit der Sächsin) und die Einheitlichkeit ihres Charakters halten genauerer Prüfung nicht stand. ${ }^{20}$ Das Mitleid, das sie Tellheim entgegenbringt und das sie zu einem scheinbar so selbstlosen Verzeihen gegenüber seiner von der "Ehre" geforderten Untreue befähigt, wenn er nur zu ihr zurückkehrt, ist letzlich so wenig über jeden Verdacht erhaben wie sein Ehrbegriff. Auch bei ihr folgt die Entscheidung zum Mitleid, wie bei ihm zur Ehre, offenbar aus einer prinzipiellen Einstellung mit vorgegebenen Verhaltensmustern. Man braucht da nur an ihr unangebrachtes Mitleid mit der Spielleidenschaft des Riccaut de la Marlinière zu erinnern, jener Karikatur Tellheims. So bemerkt wenigstens Franziska auch sonsı̊ manches an ihr, was keineswegs nur schmeichelhaft ist und ihr Verhalten gegenüber Tellheim in einem nicht nur positiven Licht erscheinen läßt. Bei genauerem Hinsehen ist ihr Charakter in der Verteilung und 'Schichtung' von Tugend und Laster nicht weniger komplex als der Tellheims.

Interessant ist in diesem Zusammenhang das Gespräch II, 1 zwischen Minna und Franziska, in dem die Kammerjungfer Gelegenheit nimmt, als Nebenperson bei ihrem Fräulein "Maximen der Weisheit anzubringen." Minna wird eingeführt als eine Liebende, die in der Beurteilung ihrer Liebe und ihres Geliebten vor allem ihr Herz sprechen lassen will. Darauf Franziska: "Das Herz, gnädiges Fräulein? Man traue doch ja seinem. Herzen nicht zu viel. Das Herz redet uns gewaltig gern nach dem Maule." Man muß sich dabei daran erinnern, mit welcher Selbstsicherheit Minna in der Szene II, 9 Tellheims Berufung auf "Vernunft" und "Notwendigkeit" zurückweist ("Aber lassen Sie doch hören, wie vernünftig diese Vernunft [...]") und ihn ihrerseits doch mit kalkulierten Mitteln des Verstandes zu bezwingen sucht. Ihr nach außen so optimistisches Zitieren der Stimme ihres Herzens ("Franziska, mein Herz sagt es mir, daß meine Reise glücklich sein wird, daß ich ihn finden werde") ist nicht weniger zweideutig als Tellheims Zuflucht zur Kategorie der Vernunft. ${ }^{21}$ Dabei entspricht Franziskas Kritik wiederum den Vorbehalten La Rochefoucaulds. Mit dem Herzen hat es nämlich eine ganz eigene Bewandtnis: "Wer seinen Verstand kennt, kennt nicht immer sein Herz." (Nr. 
103; Sch., S. 55) Also sollte sich derjenige, der sich auf sein Herz beruft, zur Vorsicht mahnen lassen: "Wir wissen bei weitem nicht alles, was wir wollen." (Nr. 295; Sch., S. 72) Das gilt umso mehr für Minna, als sie den Verstandes-Argumenten Tellheims ihre Argumente des Herzens bewußt kalkulierend entgegensetzt und dabei ganz Herr ihres Handelns zu sein glaubt: "Oft glaubt der Mensch sich selbst zu führen, wenn er geführt wird, und während sein Geist nach einem Ziele strebt, führt ihn sein Herz unmerklich einem andern zu. (Nr. 43; Sch., S. 50)

Ein solcher Selbstbetrug liegt auch dem "Streich" zugrunde, durch den Minna Teilheim "wegen [seines] Stolzes mit ähnlichem Stolze ein wenig martern" will22. ein Vorhaben, dessen problematischer Vollzug dann die beiden letzten Aưzüge ausfült. Der Grund für ihre Rache ist nicht nur, ihm eine Lehre (vgl. Nr. 410; Sch., S. 81) zu erteilen. Mit Gewißheit ist vielmehr Eifersucht zu unterstellen, und die läßt sich gerade in ihrem Fall leicht aus der Psychologie La Rochefoucaulds ableiten. Wenn sie nämlich Teliheim immer wieder der Eifersucht bezichtigt und ihn einen zweiten Othello nennt, dann ist diesem Vorwurf entgegenzuhalten: "Jedermann hat am andern auszusetzen, was man an ihm auszusetzen hat." (Nr. 567; Sch., S. 97) Wie sehr sie in der Tat ihr eigenes Laster in ihren Verlobten projiziert, kann man schon daraus ableiten, daß seine Eifersucht sich eben nicht, wie bei Othello, auf die geliebte Frau richtet. Auch wenn sie da bewuBt einen Scherz auf Kosten Tellheims machen möchte, erklärt sich der Inhalt dieses Scherzes doch am ehesten aus der Haltung, die ihr selbst die natürlichste ist, so sehr sie sie bei sich selbst zu unterdrücken versucht.

thre Eifersucht ist freilich sachlich berechtigt, und auch La Rochefoucauld zeigt für solche Fälle Verständnis: "Eifersucht ist in gewisser Hinsicht gerecht und vernünttig, da sie nur den Besitz bewahren will, der unser ist oder zu sein scheint. Neid dagegen ist Eifern über den Besitz anderer." (Nr. 28; Sch., S. 49) Warum aber will Minna ihre Eifersucht dann nicht eingestehen? Warum nicht einräumen, daß sie durch Tellheims Aufkündigung der Verlobung in ihrem Stolz getroffen ist? Franziska will es offenbar nicht recht glauben, daß die, die ihren Rache-Streich plant, so gar keine Angst hat, mit eben diesem Streich den "Besitz" ihres Tellheim auts Spiel zu setzen: "Nun, da müssen Sie ja recht sehr ruhig sein, mein Fräulein, wenn Ihnen schon wieder Streiche beifallen." 23 Franziska scheint zu ahnen, daß Minnas Behauptung, ihren Stolz aus pädagogischen Gründen nur spielen zu wollen, in Wahrheit bloßer Vorwand ist. Franziskas Einwand hätte sich also mit La Rochefoucauld auch so formulieren lassen: "Wenn wir nicht stolz wären, würden wir uns nicht über den Stolz anderer beklagen." (Nr. 34; Sch., S. 50) 
So ruhig also ist Minna in einer tieferen Schicht ihres Bewußtseins keineswegs, vielmehr ist auch sie so sehr in ihrer Eigenliebe getroffen, daß sie zur Wiederherstellung ihres Stolzes die Liebe ihres Verlobten aufs Spiel setzt. Denken wir an La Rochefoucaulds Satz: "In der Eifersucht liegt mehr Eigenliebe als Liebe." Wieder ist es Franziska, die das entsprechende Laster für Minna konstatiert, als diese ihre dem Veriobten zugedachte "Lektion" mit den Worten rechtfertigt: "Du wirst sehen, daß ich ihn von Grund auf kenne. Der Mann, der mich jetzt mit allen Reichtümern verweigert, wird mich der ganzen Welt streitig machen, sobald er hört, daß ich unglücklich und verlassen bin." 24 Franziskas knappe Antwort, laut Regieanweisung "sehr ernsthaft", heißt: "Und so etwas muß die feinste Eigenliebe unendlich kützeln." Die Ernsthaftigkeit ist natürlich Ironie, nämlich in Bezug auf das beigegebene Adjektiv; der Verdacht, Minnas Verhalten beruhe auf Eigenliebe, ist dagegen durchaus unironisch. Minnas Antwort will den Vorwurf denn auch nicht eigentlich widerlegen: "Sittenrichterin! Seht doch! vorhin ertappte sie mich auf Eitelkeit; jetzt auf Eigenliebe." Was dabei die Eitelkeit anlangt, so ist es auch hier wieder La Rochefoucauld, der sie schon vor Franziska mit der Eifersucht in Zusammenhang gebracht hatte: "Die Schmerzen der Schande und Eifersucht sind so heftig, weil die Eitelkeit nicht helfen kann, sie zu ertragen." (Nr. 446; Sch., S. 83)

Minnas Stolz hat freilich ein ganz anderes Aussehen als Tellheims, doch ist nach $\mathrm{La}$ Rochefoucauld "der Stolz [...] in allen Menschen gleich, nur die Mittel und Wege, ihn zu zeigen, sind verschieden." (Nr. 35; Sch., S. 50) Entsprechend ist Minnas Verhalten weibliche Eitelkeit, Koketterie. Sie gibt sich "ruhig" und ungetroffen, aber wie schon bei Tellheim gilt auch für sie: "Immer hält sich der Stolz schadlos und verliert nichts, selbst wenn er auf Eitelkeit verzichtet." (Nr. 33; Sch., S. 50) Um zu verstehen, was der Satz für Minna bedeutet, ist es nützlich, darauf zu achten, daß La Rochefoucauld gleich zwei Definitionen der Koketterie gibt. Die erste lautet: "Oft glauben die Weiber zu lieben, wenn sie noch nicht lieben. Die Beschäftigung mit einem Abenteuer, die Anregung, die eine Liebschaft mit sich bringt, die Neigung zur Lust sich lieben zu lassen, die Unlust des Abweisens - dies alles macht sie glauben, daß sie lieben, während sie bloß kokett sind." (Nr. 277; Sch., S. 71) Im Vergleich zu dieser Definition beherrscht Minna gleichsam eine höhere, aber keineswegs harmlosere Koketterie, der man das "Laster" nur noch schwer ansehen kann, weil es sich in eine "Tugend" verkleidet hat. Wie Tellheim seine Untreue gegenüber der Verlobten mit Fürsorge für ihren guten Ruf und ihr wirtschaftliches Wohlergehen kaschiert, so verbirgt Minna, auch vor sich selbst, ihre Unsicherheit und ihre Empörung über sein 
Verhalten hinter der äußerlich überlegenen Gewißheit ihrer beider unwandelbarer, unverbrüchlicher Treue. La Rochefoucauld definiert diese höhere Koketterie so: "Es ist eine Art von Koketterie, merken zu lassen, daß man keine hat." (Nr. 107; Sch., S. 56) So bleibt es dabei: wie Tellheim leidet auch Minna an gekränktem Stolz, und die Befriedigung dieses Stolzes motiviert zuletzt ihren nach außen hin so pädagogischhilfreich gemeinten Rache-Plan: "An den Lehren, die wir denen spenden, die Fehler begangen haben, hat der Stolz mehr Anteil als die Güte, und wir tadeln sie nicht so sehr, um sie zu bessern, als um sie zu überzeugen, daß wir selbst frei sind von solchen Fehlern." (Nr. 37; Sch., S. 50)

Aus dieser Optik bekommt also die auf den ersten Blick so positive Reaktion, mit der Minna auf Tellheims Untreue reagiert, einen neuen, bedenklicheren Aspekt. In einer schon zitierten Maxime (Nr. 107; Sch., S. 56) war begründet worden, warum sich eine Geliebte niemals über die Untreue ihres Geliebten beklagen dürfe. Die Art, in der sie es doch tut, indem sie es scheinbar nicht tut, zeugt keineswegs von dem reinen Mitleid, das wir in der Oberflächeninterpretation des vorigen Abschnitts unterstellten. Auszugehen ist vielmehr von der Maxime: "Haben unsere Freunde uns hintergangen, so dürfen wir Gleichgültigkeit bei ihren Freundschaftsbezeugungen, aber nie Teilnahmslosigkeit bei ihrem Unglück zeigen." (Nr. 434; Sch., S. 83) Minna verstößt gegen diese Maxime, wofern sie sein Unglück gerade da nicht ernst nimmt, wo sie ihm scheinbar so bereitwillig daraus zu helfen sucht. Denn wie wenig sein Unglück sachlich begründet ist, weiß sie fast von Anfang an, da die Kriegskasse ja längst Order hat, seinen Fall wieder ins reine zu bringen, und dieses Wissen wird ihr wie dem Zuschauer von Szene zu Szene nur immer mehr bestätigt. Umso dringlicher müßte ihr also einleuchten, daß sie ihm durch Vorhaltungen ihrer persönlichen, gar materiellen Hilfsbereitschaft ${ }^{25}$ nicht beikommen kann. In diesem Punkt ist sie so starrsinnigselbstgerecht wie Tellheim, wenn er nicht sehen will, daß seine Aufkündigung der Verlobung, obwohl doch gedacht als Mittel der Wahrung ihrer gesellschaftlichen und materiellen Interessen, sie dennoch verletzen muß: sie gibt sich angesichts seiner Probleme überlegen statt teilnahmsvoll. ${ }^{26}$

Mit ihrem "Streich" kalkuliert sie den indirekten Weg, der es ihr erlaubt, sein Mitleid für sie zu erwecken und inn so zu seiner früheren Liebe und Treue zurückzugewinnen. Mit diesem Mitleid verlangt sie aber am Ende von ihm genau das, was sie selbst nicht wirklich zu leisten vermag, vielmehr mit ihrer "Lektion" gerade versäumt: menschliches Verständnis für die Probleme des anderen mit seiner Eigenliebe zu haben. Weil es sich bei der Befriedigung ihrer Koketterie um ein ihr unbewußtes 
Ziel handelt, "martert"27 sie ihn mit ihrem Streich auch dann noch weiter, als sich schon ab Szene IV, 7 - ihre Kalkulation auf sein Mitleid als richtig erwiesen hat. Sie spielt mit ihm, auch sie eine Verwandte des Spielers Riccaut, ${ }^{28}$ und spielt dabei mit ihrem Glück, gerät also in Gefahr, ihr Glück zu verspielen und den Geliebten zu verlieren. Die Pari-Situation ist erst erreicht, als Tellheim annehmen muß, daß sie ihn verraten habe, daß sie sein Mitleid in Wahrheit gar nicht wolle und nur gekommen sei, mit inm "zu brechen": "die Falsche, die Ungetreue!"29

Das entscheidende Pari besteht mithin darin, daß sie, ohne es zu wollen, mit ihrem Verlobten ebenso Vabanque spielt, wie er es zuvor mit ihr getan hatte, und daß sie es ebenso aus gekränktem Stolz tut wie er. Auch auf Minna paßt also der Satz: "Oft beklagen wir uns leichthin über unsere Freunde, um im voraus unsere Leichtfertigkeit zu rechtfertigen." (Nr. 179; Sch., S. 62)

\section{$\mathrm{VI}$}

Die Frage ist von hier ab nicht nur, wie er, sondern auch wie sie aus dieser Situation wieder herauskommt. Das Mindeste ist, daß Teliheim die aufs Extrem gebrachte Probe besteht; aber erforderlich ist darüber hinaus, daß er die Probe auf eine Weise besteht, die ihr die Augen über ihr eigenes "Laster" öffnet. Doch fragen wir zu diesem Zweck zunächst, warum und in welchem Grade Tellheim am Ende vom "Laster" zur "Tugend" findet. Nach allem Bisherigen, das bereits von La Rochefoucauld zitiert wurde, kann man von vornherein davon ausgehen, daß Lessing, wenn er sich auch in diesem Punkt nach der Denkart der Maximen richtet, Tellheims schließliche "Tugend" seinem vorigen "Laster" keineswegs absolut entgegensetzen wird. Bei genauerem Hinsehen spricht La Rochefoucauld im Konditionalis einer grundsätzlich in Frage gestellten Existenz reiner Liebe, wenn er - wie oben (Nr. 244; Sch., S. 68) zitiert - die Maxime formuliert: "Gibt es eine reine Liebe, in die sich gar keine andern Leidenschaften einmengen, so hält sie sich, uns unbekannt, im innersten Herzen verborgen." Was also hat Minna, wenn die reine Liebe im innersten Herzen verborgen bleibt, nun wirklich im Herzen Tellheims entdeckt, als sie sich "den Anblick [seines] ganzen Herzens" verschaffen konnte? Offenbar dies, daß er soeben an ihr festhielt, obwohl er sie als "die Falsche, die Ungetreue" durchschaut zu haben glaubte - doch warum hielt er an ihr fest?

Die Unterstellung der "reinen Liebe" ist eine Abstraktion, an deren Stelle mit Hilfe von La Rochefoucaulds Maximen durchaus konkrete Gründe genannt werden können. Es sind vor allem zwei Maximen, die das Probiem Tellheims, nachdem er Minnas Untreue 
erkannt zu haben glaubt, als ein gleichsam seelen-ökomomisches erscheinen lassen. Die erste Maxime heißt: "Die größte Weltklugheit besteht darin, den Preis der Dinge zu kennen." (Nr. 244; Sch., S. 68) Und die zweite Maxime lautet: "Der Stolz will nichts schuldig sein, und die Eigenliebe nichts bezahlen." (Nr. 228; Sch., S. 66) Der erste Teil der zweiten Maxime wird im Lustspiel durch Tellheim immer wieder demonstriert: in seinem Verhältnis zu der Dame in Trauer, zu Just, zu Werner und vor allem natürlich auch zu Minna. Daß seine Eigenliebe hingegen nichts bezahlen will, bedeutet im Prinzip natürlich nichts anderes als eine Umkehrung der Formulierung aufgrund einer anders gewählten Perspektive. Wer etwas schuldig wird, bezahlt mit dem das Selbstgefühl schmälernden Bewußtsein seiner Schuld. Natürlich handelt es sich bei solcher Deutung gleichsam um eine Anabasis eis allo genos : vom Geldhaushalt hinauf zum Seelenhaushalt; aber erst dieser Wechsel der Ebenen vermag überhaupt den ersten Teil der Maxime sachlich zu erklären und unterscheidet im übrigen die Eigenliebe vom bloßen Geiz oder von der Knauserigkeit.

Was also, noch einmal, hat Tellheim dazugelernt oder besser: dazulernen müssen? Eben dies, daß er den "Preis der Dinge" falsch eingeschätzt hatte. Seine entscheidende Täuschung ist in der folgenden Maxime La Rochefoucaulds mindestens angedeutet: "Wer glaubt, daß er auf alle Welt verzichten könnte, täuscht sich, aber wer glaubt, daß man auf ihn nicht verzichten könnte, täuscht sich noch viel mehr." (Nr. 201; Sch., S. 63) Der Glaube, auf alle Welt verzichten zu können, entspricht dem Wunsch, niemandem etwas schuldig zu werden. Auf diesen Wunsch verzichtet Tellheim, als er aus Mitleid für die angeblich verarmte Minna, der er finanziell aushelfen möchte, seinerseits bei Werner Geld borgen will: "Nun brauch ich dich, ehrlicher Werner!" 30 Es ist derselbe Werner, dessen Hilfsbereitschaft er zuvor aus Stolz, "nichts schuldig sein" zu wollen, so hartnäckig zurückgewiesen hatte. Daß er sie dann annimmt, zeigt unwiderleglich, daß ihm die Möglichkeit zu tätigem Mitleid, also das Bewußtsein, andere (nämlich Minna) auf ihn und seine Hilfe angewiesen zu wissen, in der Tat höher stehen als der Stolz, niemandem etwas zu schulden. So muß ihn die Enttäuschung darüber, daß Minna ihn und seine Hilfe nun gar nicht zu wünschen behauptet, ${ }^{31}$ erheblich stärker treffen als die vorher für seine eigene Person unterstellte Notwendigkeit, um seines Streits mit Preußen willen auf Minna zu verzichten. Jetzt erst ist er wirklich existentiell in seiner Eigenliebe getroffen, und eben deshalb gerät er so sehr aus der Fassung, daß er gegenüber Werner, sein Geld zurückweisend und ihn aufs tiefste beleidigend, erklärt, "Galle" sei "noch das Beste, was wir haben", um dann tatsächlich selbst "vor Wut an den Fingern" zu nagen. ${ }^{32}$ Wieder liest sich eine Maxime wie ein willkommener 
Kommentar: "Man macht keinen Unterschied zwischen den verschiedenen Arten des Zornes [espèces de colères], obwohl es einen leichten und fast unschuldigen gibt, der aus der Hitze des Gemüts kommt, und einen andern sehr schuldigen, der, um ihn beim wahren Namen zu nennen, die Raserei des Eigendünkels ist [la fureur de l'orgueill]." (Nr. 601; Sch., S. 100)

Die Regieanweisung, daß Tellheim an den Fingern nage, zeigt deutlich, daß sich seine Wut hier nicht mehr gegen Minna und Werner, sondern gegen ihn selbst richtet. Er hatte den "Preis" seiner Untreue an Minna verkannt und muß ihn hier erfahren. Wenn er auf die Nachricht von der Ankunft des "grausamen Oheims", der Minna angeblich enterbt hat, sogleich wieder "zu sich selbst" kommt, um ihr gegen ihn beizustehen, so zeigt das, daß er die Gelegenheit freudig ergreift, auf seinem Mitleid zu ihr und damit auf seinem Selbstwertgefühl zu beharren.

Wie hoch ist mithin aus dem Blickwinkel La Rochefoucaulds seine Treue zu Minna an dieser Stelle zu bewerten? Hatte er sie früher verlassen in dem Bewußtsein, daß er ihrer Liebe und Treue sicher sein könne, so hält er nun zu ihr, obwohl er ihrer Untreue gewiß zu sein glaubt. Und doch ist seine Treue hier, nach der früheren Untreue, letztlich offenbar durchaus wieder Mittel zum Zweck, und der Zweck heißt Eigenliebe. La Rochefoucauld kann gelegentlich sehr negativ über die forcierte Treue um der Treue willen urteilen: "Die Gewalt, die man sich antut, in der Liebe treu zu bleiben, ist nicht viel besser als Untreue." (Nr. 383; Sch., S. 79) Doch Tellheim tut sich ja nur Gewalt an, was seinen Glauben an ihre angebliche Untreue angeht, deretwegen sie sein Mitleid eigentlich nicht "verdient". Seine Eigenliebe jedoch ist stärker als sein Abscheu, und deshalb wird sein Beharren auf dem Mitleid für ihn geradezu zu einer Frage des moralischen, ja, daraus folgend: existentiellen Überlebens. La Rochefoucauld formuliert entsprechend: "Es gibt zwei Arten von Beständigkeit in der Liebe: die eine kommt daher, daß man an der Geliebten immer neue Gründe findet, sie zu lieben, die andere, daß man sich eine Ehre daraus macht, beständig zu sein." ( $\mathrm{Nr}$. 176; Sch., S. 61) Tellheims neue Beständigkeit in der Liebe ist natürlich die zweite in dieser Aufzählung. Entscheidend aber ist, daß der neue Liebhaber dieser neuen "Ehre" sie hier nicht mehr im Munde führt, weil sie ihm nicht mehr als Vorwand und abstraktes Mittel zum Zweck dient, sondern in ihrer Verwirklichung mit dem Zweck zusammenfält.

Zu beantworten bleibt die Frage, wie Minna auf seine 'Bewährung' reagiert. Wie er von seiner Wut, so läßt auch Minna "auf einmal" von ihrer "Untreue" ab, die nicht nur gespielt, sondern in Gestalt der Koketterie, in der sie mit ihm gespielt hat, durchaus 
echt war. Ebenso echt aber ist ihr Entsetzen, als sie seine Wut sieht, und hernach ihre Erleichterung, als er von seiner selbstzerstörerischen Wut zu einer neuen Möglichkeit des Mitleids und damit "zu sich selbst" zurückfindet. Dabei ist die Relation zu beachten: Je größer ihr Entsetzen ist über das, was sie angerichtet hat, umso größer muß auch ihre Erleichterung sein, als er aus seiner Wut zu ihr zurückfindet. Diese Erleichterung bedeutet mehr als die ihr schon viel früher ermöglichte Freude darüber, daß er seinem politischen Ehrgeiz um seiner Liebe willen entsagen will - eine Leistung, die ja an sich auch nicht zu unterschätzen gewesen wäre: "Man geht oft von der Liebe zum Ehrgeiz über, aber selten kehrt man vom Ehrgeiz zur Liebe zurück." (Nr. 490; Sch., S. 87) Es bedarf jedoch des langen 5. Aufzugs, damit Minna eine tiefere, ihr eigenes Verhalten in Frage stellende Erfahrung machen kann.

Tellheims Wut ist nach dem Ausdruck La Rochefoucaulds nur allzu offensichtlich eine "sehr schuldige" (Nr. 601; Sch., S. 100), und sie ist Ausdruck einer Schwäche, die - wiederum nach La Rochefoucauld - "leicht in Bösartigkeit umschlägt." (Nr. 479; Sch., S. 86) So könnte man die schließliche Treue Tellheims zwar vielleicht formal ins Positive wenden mit dem Satz: "Niemand verdient das Lob der Güte, wenn er nicht auch die Kraft besitzt, böse zu sein; jede andere Güte ist meist núr Trägheit oder Willensschwäche." (Nr. 237; Sch., S. 67) Doch muß Minna eben zunächst einmal gleichsam am eigenen Leib, oder schlimmer: an der eigenen Seele spüren, wie gefährdet er ist und daß seine Fähigkeit, "böse zu sein", nicht die Folge seiner Kraft, sondern seiner Schwäche ist. Das Mitleid, das hier von ihr verlangt ist, unterscheidet sich kategorial von dem früheren, mit dem sie inn von seiner Preußenfixiertheit befreien wollte, denn es ist nicht mehr ein Mitleid aus insgeheim überheblicher Selbstgewißheit, sondern aus einer Erfahrung, in der zugleich ihr eigenes Selbstbewußtsein existentiell bedroht ist. Bedroht aber ist es aus dem gleichen Grunde wie das Selbstgefühl Tellheims, der sein Mitleid verschmäht glaubt. Denn wofern er auf seiner 'falschen' Meinung von ihr beharrt, ist sie in Gefahr, mit dem Mitleid, das sie mit seiner "bösen" und "schuldigen" Wut hat, auch sich selbst von ihm zurückgewiesen zu sehen. Allein diese Erfahrung der Bedrohung und des Verlustes, die ihn von seinem selbstzerstörerischen Stolz heilt, heilt auch sie und ihr Mitleid von jener Koketterie, die zwar eine Koketterie höherer Ordnung, aber auch höchster Gefährdung menschlicher Gemeinschaft ist. Es ist dies die Koketterie, von der La Rochefoucauld sagt: "Wahre Freundschaft verdrängt den Neid, wahre Liebe die Koketterie" (Nr. 376; Sch., S. 78), und emphatisch steigernd: "Das größte Wunder der Liebe: von der Koketterie zu heilen." (Nr. 349; Sch., S. 76) 
Kehren wir zum Schluß noch einmal zurück zu Chassirons Réflexions sur le Comique-larmoyant. Chassiron stellt als eine seiner wichtigsten Thesen auf, es komme allein "den Nebenpersonen zu, die Maximen der Weisheit anzubringen", 33 und Chassiron beruft sich dabei auf Beispiele: "So hat Molière dem Freunde des Misanthropens, dem Schwager des Orgons, dem Bruder des Sganarelle etc. die Sorge aufgetragen, uns die Grundsätze der Tugenden vorzulegen, die er zu dem Gegenstande unserer Nachahmung machen wollte; seine Originale aber hat er mit allen Zügen der Satyre, des Tadels und des Lächerlichen überhäuft, von welchen er glaubte, daß sie sowohl zu unserm Ergötzen, als zu unserm Unterrichte dienen könnten." ${ }^{34}$ Diese Trennung von tadelhaft Lächerlichem und moralisch Nachahmenswertem hat Lessing in seinen beiden Hauptfiguren aufgehoben, wenn auch noch auffällig bleibt, wieviele Maximen dem Kammermädchen Franziska in den Mund gelegt sind. Was aber die beiden Hauptfiguren und zumal Tellheim anlangt, so begnügt man sich in diesem Zusammenhang im allgemeinen festzustellen, daß es sich eben um eine Charakter- und nicht um eine Typenkomödie handle. Von der Maximenlehre La Rochefoucaulds aus können wir nun aber genauer sagen, daß Tellheims Charakter gleichsam übereinander drei verschiedene moralische Schichten aufweist: an der Oberfläche seine "Maske" der gekränkten (nicht etwa nur beleidigten) Ehre; weiter die darunter verborgene Eigenliebe, die von Minna als starre Eifersucht diagnostiziert wird; sowie drittens die wiederum von Minna noch unter diesem zweiten Charakter vorausgewußte und nach Kräften beförderte Schicht der unbedingten Treue (sprich "wahren Liebe") jenseits von gekränktem Ehrgefühl und Eifersucht. Ebenso vielschichtig setzt sich der Charakter Minnas zusammen. Vor sich selbst und ihrer Umwelt demonstriert sie die Fähigkeit zu überlegen-verständnisvoller Hilfsbereitschaft, doch ist unter ihrem tätigen Mitleid der heimliche Charakterzug rachebedürttiger Eifersucht verborgen, der ihr selbst keineswegs ganz unbewußt ist, über dessen Ausmaß sie sich jedoch nicht entfernt im klaren ist, den sie vielmehr zu Unrecht ganz unter Kontrolle zu haben glaubt. Wieder ist, wie bei Tellheim, die Eigenliebe das Movens jener zweiten Charaktereigenschaft. Was aber entspricht bei Minna Tellheims dritter, 'tiefster' Charakterschicht, die wir soeben als die Schicht unbedingter Treue und "wahrer Liebe" definiert haben?

Wir haben uns in dieser Definition, was Tellheim anlangt, ganz von Minnas Worten leiten lassen. Die Frage, was Minna denn wirklich zuletzt in Tellheims "innerstem Herzen" sehen kann, ist aber auf diese Weise offenbar solange nicht befriedigend 
beantwortet, wie wir nicht wissen, kraft welcher moralischen Autorität Minna selbst zu solcher Wertung berechtigt ist.

Natürlich geht es in diesem Stück nicht nur um die allmähliche Entlarvung verborgener Charaktereigenschaften der Protagonisten. Die dramatische Handlung verlangt vielmehr den Progreß vom "Laster" zur "Tugend", wobei dieser wieder vom Erkenntnisprozeß der Protagonisten abhängig gemacht wird, der offenbar zuletzt ihr Fortschreiten zur "reinen Liebe" ermöglichen soll - mit aller Einschränkung und Skepsis, mit der schon La Rochefoucauld diesen Begriff gebraucht. Es muß hier deshalb noch einmal genauer nach dem Erkenntnis-Fortschritt der beiden Protagonisten gefragt werden.

Die existentielle Erleichterung über die bestandene Gefahr ist zwar bei beiden Protagonisten unzweifelhaft. Tellheim erwartet jedoch darüber hinaus von Minna Reue: "Ha, wenn ich wüßte, daß Sie es bereuen könnten!" Das Wort ist dabei gar nicht so ungeschickt, um zu beschreiben, was auch Minna sich nach dem glücklichen Ende ihrer gefährlichen Intrige für ihn erhofft, nämlich den Vorsatz, seine Untreue niemals zu wiederholen: "Dieses zur Probe, mein lieber Gemahl, daß Sie mir nie einen Streich spielen sollen, ohne daß ich Ihnen nicht gleich darauf wieder einen spiele. ${ }^{35}$ Das entspricht genau dem Gedanken La Rochefoucaulds: "Damit wir immer gut sein könnten, müßten die andern glauben, niemals ungestraft böse gegen uns sein zu können." (Nr. 662; Sch., S. 102)

Interessant ist gleichwohl, daß Tellheim und Minna, die doch beide gerade erst durch den andern aus einer selbstverschuldeten Krise befreit wurden, die Schuld gleich wieder dem andern zuschieben. Minna ist freilich zuvor ehrlich genug zu bezeugen, daß sie ihr Glück allein Tellheim verdanke: "Umarmen Sie Ihre Minna, Ihre glückliche Minna; aber durch nichts glücklicher als durch Sie!" Außerdem ist die eben zitierte Drohung, daß sie ihm auf jeden seiner Streiche mit einem eigenen antworten werde, doch merklich verschieden von der früheren Ironie, mit der sie ihm im Auftritt IV, 6 verkündet hatte, die Lähmung seines rechten Armes sei für sie von Vorteil, da er umso weniger sicher vor ihren Schlägen sein werde. Zwar war das im Scherz gesagt, doch in einem überlegen vorwurfsvollen Ton gesprochen, für den hier am Ende kein Anlaß mehr besteht. Hat sie doch gerade erst erlebt, wie überheblich es von ihr gewesen war, zu Beginn, bei der Nachricht von Tellheims Gegenwart im Wirtshaus, gegenüber Franziska zu äußern: "Er jammert dich? Mich jammert er nicht. Unglück ist auch gut. Vielleicht, daß ihm der Himmel alles nahm, um ihm in mir alles wieder zu geben." ${ }^{36}$ Sie war es doch gewesen, die inn mit ihrem "Streich" in die tiefste Wut 
und Verzweiflung gestoßen hatte.

Und auch in Tellheims Bewußtsein ist wenig später die Erinnerung an seine eigenen Fehler keineswegs ausgelöscht. Denn zwar war er nach seinem Ausbruch selbstzerstörerischer, verzweifelter Wut bei der ersten sich bietenden Gelegenheit wieder in das erlösende Mitleid zu Minna geflüchtet und eben damit "auf einmal" wieder "zu sich" gekommen. Im nächsten Auftritt jedoch scheint er gegenüber dem Grafen Bruchsal dieses Zu-sich-selbst-Kommen auch selbst als einen immer noch unabgeschlossenen Prozeß zu begreifen: "Lassen Sie mich zu mir selbst kommen, mein Vater!" Dieser Bitte geht die verwunderte Feststellung des Grafen gegenüber Minna voraus, daß ihm ihr Verlobter stumm erscheine. Offenbar soll es sympathische Unsicherheit sein, die nun aus Tellheims Schweigen spricht und dem früheren starrsinnigen Beharren auf seinem Recht ganz entgegengesetzt ist. "Wir reden wenig", sagt La Rochefoucauld, "wenn die Eitelkeit uns nicht reden macht." (Nr. 137; Sch., S. 58) Und weiter: "Schweigen ist der sicherste Weg für den, der sich selbst nicht traut." (Nr. 79; Sch., S. 53) Wenn es denn also für Tellheim einen Fortschritt vom "Laster" zur "Tugend" gibt, so ist es offenbar der zu jener Demut, von der La Rochefoucauld in Maxime 358 sagt: "Demut ist das wahre Kennzeichen christlicher Tugenden. Ohne sie bleiben uns all unsere Fehler, und sie werden nur vom Stolz bedeckt, der sie andern und auch uns selbst verbirgt." Das Schweigen Tellheims, der noch vor so kurzem an Minnas Liebe gezweifelt hatte, verrät an dieser Stelle mithin mehr über seinen neuen Seelenzustand $^{37}$ als die bloße Erleichterung, mit der er nach Minnas Enthüllung ihrer Ringintrige ausruft: "O Komödiantinnen, ich hätte euch doch kennen sollen." Denn zwar ist richtig, daß man "bisweilen weniger unglücklich [ist], von der Geliebten getäusch zu werden als enttäuscht" (Nr. 395; Sch., S. 80), doch bleibt bei aller Einschränkung seiner Fähigkeit zu bewußter Reue nun immerhin etwas übrig, was mehr ist als die bloße Erieichterung über das scheinbar harmlose Komödiantentum von Minnas Intrige.

Es ist zunächst dies: "Unsere Reue ist nicht so sehr Bedauern des Bösen, das wir getan, als Furcht vor dem, das uns daraus erwachsen kann." (Nr. 180; Sch., S. 62) Seine neue Demut ist nicht abstraktes Prinzip, sondern die unmittelbare Folge seiner Konfrontierung mit den Ergebnissen seines falschen Stolzes, den er mit dem Wort "Ehre" kaschiert hatte. Es bleibt jedoch nicht nur dabei, daß Lessing hier das Tugend-Prinzip, das schon von La Rochefoucauld als christliche Demut apostrophiert worden war, zugleich mit dem komplementären Laster der Hybris bzw. Superbia der traditionellen Tragödien- wie Komödien-Poetik zusammengehen läßt. Unbestreitbar besteht der Erkenntnisfortschritt Tellheims wie Minnas in dem neuen Wissen, was sie 
jeweils am anderen haben und wie sehr sie seiner bedürfen. Das beinhaltet zugleich die Erkenntnis, daß sie im allzu leichtfertigen Umgang mit dem Partner am meisten sich selbst gefährden.

Auf der Ebene von Tugend und Laster ergibt sich so ein doppelter Fortschritt: erstens die Überwindung des amour-propre in dessen letztlich selbstzerstörerischer Form, sowie zweitens, als inhaltliche Zielgebung, der Schritt von einer egozentrischen zu einer sozialen Haltung. Der Vorzug der von Lessing in seinem Lustspiel gewähiten Dramaturgie ergibt sich freilich gerade aus der umgekehrten Perspektive, daß er nämlich auf diese Weise die geforderte soziale Haltung aus einer höheren, richtig verstandenen Eigenliebe abzuleiten vermochte, ohne sich auf abstrakte Vernunftprinzipien oder religiöse Gebote ${ }^{38}$ berufen zu müssen. Erinnern wir uns an La Bruyères bekanntes Diktum, daß er selbst die Menschen vernünttig machen wolle, während Pascal sie gläubig und La Rochefoucauld sie selbstsüchtig gemacht hätten, dann ist diese Aussage ganz offensichtlich ungerecht gegenüber dem letzteren. Zugleich aber macht sie deutlich, wieviel Lessing für seine Minna von Barnhelm den Maximen La Rochefoucaulds zu verdanken hatte. Es war die Möglichkeit, eine soziale Moral weder aus den Geboten einer positiven Religion, noch aus abstrakten Vernunftprinzipien, sondern eben aus dem schon von La Rochefoucauld vertretenen positiven Prinzip der Eigenliebe abzuleiten. Das bedeutet den wohl wichtigsten Fortschritt seines Lustspiels gegenüber der traditionellen Dramaturgie der Aufklärungs-Komödie. Zum einen nämlich überwand er auf diese Weise die bis dahin vorherrschenden lustspieltypologischen Beschränkungen der Charakter-Lehre des Theophrast und seiner Nachfolger, zum anderen die immer wieder von der Aufklärung versuchte und weithin kūnstlich gebliebene Anpassung der Affektenlehre des Aristoteles an aufklärerische Erziehungsideale.

Natürlich gilt dieser letzte Hinweis auf Aristoteles besonders für den MitleidsBegriff. Lessing war, was die Einsetzung des Mitleids als dramaturgisches Prinzip anlangt, in Minna von Barnhelm so erfolgreich wie in keinem seiner anderen Dramen. Er hat eben damit, zumindest für seine eigenen Fähigkeiten als dramatischer Autor, die zu Beginn zitierte Aussage des 77. Stücks derHamburgischen Dramaturgie selbst widerlegt, daß die Tragödie besser als die Komödie geeignet sei, "unser Mitleid und unsere Furcht [zu] reinigen." Dieser Erfolg wider die eigene Theorie ist offenbar vor allem darauf zurückzuführen, daß er für die Realisierung des wichtigsten dramaturgischen Ziels dieses Stücks, nämlich die Entlarvung scheinbarer Tugenden als Laster und ihre anschließende Verwandlung in soziale Tugenden, nicht so sehr vorgegebene Drama- 
turgien oder themenverwandte Lustspiel-Vorlagen, sondern in erster Linie die Maximen La Rochefoucaulds adaptierte. Die so gelungene Verwandlung von Lustspieltypen in Lustspielcharaktere scheint sich keinem anderen Umstand so sehr zu verdanken wie der von La Rochefoucauld vertretenen Lehre von der explosiv labilen, aber gleichwohl positiv entwicklungsfähigen, psychologischen und moralischen Vielschichtigkeit des menschlichen Charakters. Begriffe wie Ehre und Vernuntt erscheinen da ebensowenig wie die Begriffe Herz und Mitleid als vorgegebene feste Größen, sondern als Zielbegriffe, deren Verwirklichung zwar als annäherungsweiser Prozeß, nicht aber als grundsätzliche Einstellung mit gesicherten Verhaltensregeln zu denken ist.

Eben dies muß in den Augen Lessings der moralische Impetus des Mottos gewesen sein, das La Rochefoucauld seiner Maximen-Sammlung vorangestellt hatte: "Unsere Tugenden sind meist nur verkappte Laster." Zum System ausgearbeitet war diese Lehre bei La Rochefoucauld natürlich nicht; es bedurfte des systematischen ${ }^{39}$ Zugriffs eines Lessing, sie in der aphoristischen Maximen-Sammlung des Moralisten zu entdecken und für seine Lustspieldramaturgie nutzbar zu machen. Wie uns also die Maximen helfen können, Minna von Barnhelm zu verstehen, so hat uns umgekehrt auch Lessing in seinem Stück einen eigenen Schlüssel zum Verständnis La Rochefoucaulds geliefert. ${ }^{40}$ Ohne ihn wäre inm der Durchbruch zum deutschen Prototyp der "ernsten Komödie" kaum gelungen, auch wenn man Chassiron recht geben will, daß es vornehmlich "die Wahl und die Mischung der Farben, die Stellung und der Ausdruck der Personen" sind, die der Komödie "Namen, Form und Wesen erteilt haben." 41

\section{Anmerkungen}

$1 \mathrm{H}$. Steinmetz, "Minna von Barnhelm oder die Schwierigkeit, ein Lustspiel zu verstehen", Wissen aus Erfahrungen, Festschrift für Herman Meyer, Tübingen 1976, S. 147. Für peripher in Minna von Barnhelm erklärt das Ehrmotiv A. M. Reh, Die Rettung der Menschlichkeit. Lessings Dramen in literaturpsychologischer Sicht, Bern 1981, S. 255. Er stellt richtig fest, daß "zum Zeitpunkt des Handlungsbeginns die Ehrenkränkung [. . . ] nur noch eine Fiktion war, nur noch in Tellheims Vorstellung existierte", doch ist seine Folgerung, daß deshalb "die von der Forschung so sehr in den Mittelpunkt gerückte Frage der Ehre diese ihre Mittelpunktsbedeutung [verliert] und peripher [wird]", offenbar allzu radikal oder doch mißverständlich. Die Ehrenkränkung ist - eben als nur in der Vorstellung existierende - gerade aus psychologischer Perspektive von größtem Interesse.

2 Nur am Rande kann ich hier auf die Versuche eingehen, die Lösung von Tellheims Schwierigkeiten mit seinem Ehrbegriff auf einer ökonomischen oder gar 
finanztechnischen Ebene zu finden. Erwähnt seien: H. C. Seeba, "Die Sache der Ehre: Minna von Barnhelm", H. C. S., Die Liebe zur Sache. Öffentliches und privates Interesse in Lessings Dramen, Tübingen 1973, S. 65-85; H. Schlaffer, "Tragödie und Komödie. Ehre und Geld. Lessings Minna von Barnhelm, H. S., Der Bürger als Held, 1973, S. 86-125, im folgenden zitiert nach dem Wiederabdruck in $\mathrm{H}$. Steinmetz (Hrsg.), Gotthold Ephraim Lessings 'Minna von Barnhelm', Dokumente zur Rezeptions- und Interpretationsgeschichte, Königstein/Ts. 1979; G. Müller-Waldeck und Wolfgang Niesler, "Verhältnisse und Verhalten. Zur Diskussion um Lessings Minna von Barnhelm, WB 28, 5 (1982), S. 169-76; M. Lehrer, "Lessing's Economic Comedy", Seminar XX (1984), S. 79-94. Die Vereinfachungen in Seebas Ansatz moniert mit Recht G. A. Guidry, "Money, Honor and Love: The Hierarchy of Values in Lessing's Minna von Barnhelm", Lessing Yearbook XIV (1982), S. 177 und S. 181. Der Einwand von Guidry müBte auch M. Lehrer treffen, der an der These der "final money-redemption" festhält, auch wenn er das Geldmotiv wegen Tellheims Zugehörigkeit zum Adel von Lessing ironisiert sehen möchte. Zu Schlaffers Thesen vgl. unten die Anmerkungen 14 und 16, zu Müller-Waldeck und Niesler die Anmerkung 20.

3 Das gilt für die Ausgabe von La Rochefoucaulds Maximen aus dem Jahre 1678, die im folgenden vorrangig herangezogen wird.

4 In einer Rezension des Jahres 1755 in der Berlinischen privilegierten Zeitung charakterisiert Lessing eine von ihm dem Publikum vorgestellte zeitgenössische Maximensammlung mit der Bemerkung, der Autor dieses "Mischmasch von verschiednen Gerichten" sei "kein Rochefoucault", und er illustriert das mit einer Reihe von entlarvenden Zitaten. (Gotthold Ephraim Lessings sämtliche Schriften, hrsg. von K. Lachmann, 3. Aufl. besorgt von F. Muncker, Band 7, Berlin 1891, S. 30-31).

5 Lessing, Werke, München 1973, hrsg. von H. G. Göpfert, Band IV, S. 26.

6 Die deutsche Übersetzung ist entnommen aus: Die französischen Moralisten, Nördlingen 1973, Band 1, hrsg. und übersetzt von F. Schalk, S. 43-104. Die französischen Zitate und die Nummern der Maximen gebe ich nach der Ausgabe der Réflexions ou sentences et maximes morales von 1678, die samt den unterdrückten Maximen abgedruckt ist in La Rochefoucauld, Oeuvres complètes, Paris 1957, Bibliothèque de la Pléiade, vol. 24, S. 389-502.

7 H. Steinmetz, "Emotionalität versus Rationalität: Gegensätze zwischen Theorie und Praxis bei Lessing", E. P. Harris und R. E. Schader (Hrsg.), Lessing in heutiger Sicht. Lessing-Konferenz in Cincinnati, Ohio 1976, Bremen und Wolfenbüttel 1977, S. 168: "Lessings Dramenpraxis ist seiner Theorie einen Schritt voraus. Seine Tragödien und Komödien stellen den aufklärerischen Welt- und Wirklichkeitsentwurf schon wieder in Frage, unterwerfen ihn kritischer Auseinandersetzung." Ich würde stattdessen eher formulieren, daß Lessing in Minna von Barnhelm die ldee der Aufklärung kritisch differenzierend weitertreibt und $\mathrm{da} B$ der dabei erreichte Fortschritt vor allem der Verfeinerung des psychologischen Denkens zu verdanken ist. (Sie ist, wie sich zeigen wird, auch die Voraussetzung für den hier von Lessing erreichten Fortschritt in der praktischen Dramaturgie des Lustspiels.) Damit widerlegt Lessing die von L. Hippeau, Essai sur la morale de La Rochefoucauld, Paris 1967, S. 244 aufgestellte 
Behauptung: "Les hommes du XVIII siècle ne peuvent plus, comme Montaigne, Pascal et La Rochefoucauld, accepter une solution qu'on adopte faute de mieux. Ce qui leur interdit de retrouver La Rochefoucauld, c'est cette religion du progrès qu'on a vu naître avec Descartes."

8 Der von Lessing gewählte Weg, in seinem Lustspiel komische Effekte dadurch zu erzielen, daß er seine Hauptfiguren Tragödie spielen ließ, hat gewiß zu dem häufigen Mißverständnis des Stücks als einer Tragikomödie oder gar heimlichen Tragödie beigetragen.

9 J. Schröder, Gotthold Ephraim Lessing. Sprache und Drama, München 1972, S. 239.

10 Das gilt also auch für Tellheim, und zwar nicht etwa nur für sein Verhalten gegenüber der Dame in Trauer, sondern schon für seine Begründung, mit der er vor sich selbst auf Minna verzichten will, um sie vor den Folgen seiner widrigen "Umstände" zu bewahren. A. Reh (Anm. 1, S. 280), sich auf eine Aussage von P. Demetz beziehend, erinnert daran, da $B$ "das Wort Mitleid, von dem Tellheim ausdrücklich sagt, daß 'es Minna sich nicht beleidigen lassen' soll, 'jene ganz besondere Kraft oder gar jenen Affekt [bezeichnet], welche seine Seele den Eindrücken der Zärtlichkeit wieder öffnen." Schon in bezug auf Tellheims Verhalten gegenüber den Sächsischen Ständen, denen er Geld für ihre Kontributionszahlung vorscho $B$, erklärt F. J. Lampert, Lessing and the Drama, Oxford 1981, S. 32: "[. . .] his very compassion and generosity have been misconstrued, and have thus led to his present apparent disgrace."

11 Szene IV,6 (Lessing, Werke, München 1970, hrsg. von H. G. Göpfert, Band I, S. 680. Stellenangaben aus dem Stück im folgenden nur noch nach Akt, Szene und Seitenzahl). - Richtig betont Seeba (Anm. 2, S. 74-75) die Berechtigung von Minnas "Zweifel an der moralischen Substanz des [sc. von Tellheim] zu oft bemühten Ehrbegriffs [. . . ] Die lebendige Sache ist zum Wort erstart, das als Leerformel beliebig wechselnde Inhalte deckt." Sehr einleuchtend sind deshalb auch Seebas Bedenken gegen die moralische Tabuisierung von Tellheims Ehrbegriff bei Raimund Belgardt, "Tellheim's Honor: Flaw or Virtue? A re-interpretation", GR 42 (1967), S. 16-29.

12 Ibid.

13 Schlaffer (Anm. 2, S. 199) sieht das Konkurrenzverhältnis zu abstrakt: "Den besseren Ausgang verstellt vorerst eine Nebenbuhlerin [sc. Minnas], der Tellheim leidenschaftlich, 'mit starren Augen', verfallen ist: die Ehre."

14 Hier urteilt Schlaffer (Anm. 2, S. 210) offenbar allzu arglos, wenn er erklärt: "[...] daß Tellheim Geld verachtet, verleiht ihm eine besondere Würde, weil so sein innerer Wert von den äuBeren Dingen unabhängig bleibt." Wenn man dies berücksichtigt, schrumpft auch der Gültigkeitsbereich von Schlaffers Folgerung, die besagt: "'Innerer Adel' ist ein bürgerliches Ideal. Ist das Falsche des Vergangenen als 'Gespenst der Ehre' abgetan, darf das Wahre des Vergangenen als 'Rechtschaffenheit und Edelmut' bestehen." (Ibid.)

15 III, 12, S. 662. 
16 Das hindert nicht, daß Schlaffer (Anm. 2, S. 209) angesichts von Tellheims objektiven Verdrehungen der Wirklichkeit erneut zu arglos argumentiert, wenn er erklärt: "Lessings Einwände [sc. gegen das Ehrprinzip], durch Minnas Mund vorgebracht, betrafen die Übertreibungen, nicht die Substanz [...] In der Ehrlichkeit ist der Keim der Ehre bewahrt." Es geht im Stück ja gerade nicht um Tellheims guten Willen, sondern um die entlarvende Differenz zwischen seinen theoretischen Äußerungen (etwa in der Szene III, 10 in seinen Ermahnungen an Werner, "daß man über einen gewissen Punkt mit dem Frauenzimmer nie scherzen muB") und seinem tatsächlichen Verhalten, das ihm erlaubt, es in eben diesem Punkt (der Treue gegenüber der Verlobten) selbst keineswegs so genau zu nehmen, sei es auch aus subjektiv ehrenwerten Gründen.

17 Das körperliche Gebrechen ist eine Kriegsverwundung, die Tellheim im Kampf um seine "Ehre" 'gebrauchen' kann. Für sein seelisches Gebrechen aber ist die Verwundung letztlich so wenig verantwortlich wie die "materiellen Bedingungen", die ihn nach Schlaffer (Anm. 2, S. 203) "in unglückliche 'Umstände' gebracht [haben]." Es ist wichtig, hier zwischen Anlaß und Ursache zu unterscheiden: die eigentliche Ursache für Tellheims Probleme mit den "Umständen" liegt in seinem Charakter.

$18 \mathrm{~V}, 12, \mathrm{~S} .700-701$

19 IV, 1, S. 664.

20 Steinmetz (Anm. 1, S. 147) stellt richtig fest: "Von der so vielzitierten und vielgepriesenen Sicherheit und Überlegenheit Minnas bleibt letztlich nur wenig übrig. Zwar gibt sie sich überlegen und sicher, aber damit suggeriert sie dem Zuschauer und sich selbst ein falsches Bild von den ihr tatsächlich zur Verfügung stehenden Möglichkeiten zur Lösung des Konflikts." Steinmetz (S. 149) sieht freilich nicht die Schwierigkeiten, die sie mit ihrem Charakter hat, sondern nup die Schwierigkeiten Tellheims mit seinen "Umständen", mit denen auch sie zu kämpfen hat und die sich dann angeblich allein durch das königliche Handschreiben lösen. Das letztere Mißverständnis findet sich übrigens auch bei H.-G. Werner, "Komödie der Rationalität. Zu Lessings Minna von Barnhelm", WB XXV,11 (1979), S. 55, dem dann Müller-Waldeck und Niesler (Anm. 2, S. 176) entgegenhalten, die entscheidende Lösung bringe vielmehr das Auftreten des Oheims. Für beides, die Überbewertung nicht nur des königlichen Handschreibens, sondern auch des Eintreffens von Minnas Oheim, ist die Bemerkung Seebas (Anm. 2, S. 73) hilfreich, daß schon Hans Mayer die Intervention des Königs "zu den märchenhaften Zügen des Stückes" gezählt habe, die den eigentlichen Konflikt nicht beeinflussen.

21 Eine rein positive Bewertung Minnas bietet die Untersuchung von F. O. W. Röhrs, Narrative Strukturen in Lessings Dramen. Eine strukturalistische Studie, Hamburg 1980, S. 234: "Die heroisch-altruistische Verhaltensdisposition Tellheims verschuldet das Zustandekommen des Hindernisses und setzt sich dadurch negativ von der normalistisch-mutualistischen Verhaltensweise ab, die Minna vertritt, mit deren Bemühen, das Hindernis zu überwinden, der Rezipient sympathisiert." Bei Beatrice Wehrli, Kommunikative Wahrheitsfindung. Zur Funktion der Sprache in Lessings Dramen, Tübingen 1983, S. 120-22, kann man gar lesen: "Der Triumph Minnas als der wahrhaft Vernünftigen suggeriert dem 
Leser die Möglichkeit eines vernünftigen Daseins [. . .] Mit ihr (allerdings nur mit ihr) als positiver Heldin wird die Möglichkeit einer noch intakten Gesellschaft suggeriert, die 'Tugend und Vorsicht' [. . . ] zu ihrem Garanten macht." Entschieden richtiger ist da das Urteil Guidrys (Anm. 2, S. 183-84), der zwar betont, Minnas persönliche Liebe sei das entscheidende Gegengewicht gegen das potentielle Übergewicht der Ehre bei Tellheim, dann aber doch - wenn auch eher im Vorübergehen - feststellt: "[Minna] carries the farce one step too far and almost succeeds in turning it into a tragedy. There can be no doubt that here Minna shows herself in no way to be Tellheim's better." Vom dramaturgischen Gewicht des Spiel-Endes in der Ökonomie des Dramas her gesehen ist es gerade diese letzte Bemerkung über Minna, die genauere Erklärung verlangt.

22 III, 12, S. 663.

23 III, 12, S. 663.

24 IV, 1, S. 664.

$25 \mathrm{Vgl}$. ihren Tadel an Tellheim: "Denn auch seiner Geliebten sein Glück nicht wollen zu danken haben, ist Stolz, unverzeihlicher Stolz!" (III, 12, S. 662).

26 Vgl. Schlaffers (Anm. 2, S. 203) Wort über Minna, daß sie "mit Absicht an Tellheims persönlicher Problematik vorbeisieht."

27 III, 12, S. 663.

28 Zu Minnas Neigung zum Spiel vgl. F. Martini, "Riccaut - Die Sprache und das Spiel in Lessings Minna von Barnhelm", F. M., Lustspiele und das Lustspiel, Stuttgart 1974, S. 64-104.

29 V, 10, S. 698.

$30 \mathrm{IV}, 8$, S. 683.

31 V, 10, S. 698

32 V, 11, S. 700 .

33 Lessing IV, S. 27.

34 lbid.

$35 \mathrm{~V}, 12$.

$36 \quad I I, 7$.

37 Vgl. gegenüber dieser Deutung H. Steinmetz (Anm. 1, S. 147): "Tellheim wird [...] keineswegs erzogen oder geheilt. Die Intrige bewirkt auch nicht die geringste Änderung seiner grundsätzlichen Einstellung." Genauso urteilt H.-G. Werner (Anm. 20), daß sich "im Stück kein Erziehungs- oder Läuterungsvorgang nachweisen läßt." Bei Reh (Anm. 1, S. 243) heißt es dagegen richtig: "Was sich 
[sc. in den Charakteren Tellheims und Minnas] ändert, ist ihre Einstellung zum Mitmenschen und damit zu sich selbst, eine Anderung, die durch Erkenntnis, durch die Bewußtwerdung des 'Exzesses' möglich wird, in den der Charakter geraten war." Und: "Von Lessings Dramaturgie her ist diese Wirkung eine kathartische" (S. 279), die "in psychologischer Sicht als therapeutische Wirkung [erscheint]." (S. 280) Reh gibt aber keine Erklärung dafür, wie und warum Minnas "Täuschungsspiel" den "Bruch" in Tellheims Persönlichkeit heilen kann. (Ibid.) Weiter erklärt er zwar, daß in Minna Licht und Schatten gut verteilt seien, doch kommt die Erläuterung der Schatten dabei zu kurz. Außer der "Übertreibung", in der sie den "Scherz" zu weit getrieben habe (S. 282), erwähnt er im Anschluß an Martini auch ihre Spielleidenschaft. Die aber erscheint in der Bewertung Martinis ganz harmlos, ja edel, wenn sie nur "gegen Tellheim für Tellheim, für sein und ihr Lebens- und Liebesglück nicht um der Täuschung willen, sondern aus der Wahrhaftigkeit seines und ihres Herzens heraus" inszeniert ist.

38 Wie ich in Minna von Barnhelm nicht die Bedeutung der ökonomischen Fakten leugne, sondern nur ihre Überbewertung für falsch halte, so übersehe ich auch nicht das Vorhandensein religiöser Motive, halte sie aber dramaturgisch im Stück für weniger zentral als etwa in Kleists Zerbrochnem Krug. (Zur Bedeutung der religiösen Motive in Kleists Komödie vgl. $\mathrm{H}$. Delbrück, Kleists Weg zur Komödie, Tübingen 1974, passim.) Eine religiöse Deutung der Minna von Barnhelm liefert J. Schröder (Anm. 9, S. 243-247.) Bei F. J. Lampert (Anm. 10, S. 44-45) heißt es: "For [Lessing] the happy ending of the play is [...] representative of a providential order, but he believed profoundly that that order ruled the world in which we actually live [. . . ]"

39 Wie verführerisch es ist, in La Rochefoucaulds Maximen nach einem zugrunde liegenden System zu suchen, sieht man in unserer Zeit etwa bei P. E. Lewis, La Rochefoucauld. The Art of Abstraction, Ithaca und London 1977, S. 67: "It should be clearly understood that the rehabilitation of the traditional theory of self-love by no means entails a claim [. . . ] that La Rochefoucauld was intent on exposing a rigid, doctrinaire system. Indeed [. . . ] MS 1 suggests that it should simply be read as a text of theoretical import, as the potential basis or source of a theory to be derived by the analytical reader." L. Hippeau (Anm. 7, S. 241) findet den folgenden Grund dafür, daß La Bruyère La Rochefoucauld nicht richtig verstanden habe: "[La Bruyère] a beaucoup de finesse dans l'observation, mais, habile á analyser, il est peu capable de synthèse."

40 Lessings Leistung ist hier unschwer zu ermessen, wenn man seine an La Rochefoucauld geschulte Behandlung der Coquetterie in Minna mit La Rochefoucaulds Bild der Frau vergleicht, wie es uns in einer modernen Untersuchung unter der Kapitelüberschrift "Psychological investigations" - von Odette de Mourgues, Two French Moralists. La Rochefoucauld and La Bruyère, Cambridge 1978 , S. 43 vorgestellt wird: "The most glaring proof of [La Rochefoucauld's] lack of imagination and curiosity is to be found in the maximes on women [ . . .] They stand apart, reduced to a few conventional traits: coquetterie and intellectual inferiority. They are required to be young, beautiful and chaste. Love is however the only passion which can be tolerated in them but even so, most of the time their love is not a genuine feeling but another form of coquetterie. This over-simplification of female psychology indicates that La Rochefoucauld remains 
on the level of social conventions."

$41 \mathrm{Vgl.} \mathrm{oben} \mathrm{S.} \mathrm{65.-} \mathrm{Zu} \mathrm{Lessings} \mathrm{Entwicklung} \mathrm{des} \mathrm{Lustspiels} \mathrm{"in} \mathrm{the} \mathrm{direction} \mathrm{of}$ realism" vgl. Lampert (Anm. 10, S. 51). 